\title{
Specificity of $M$ and L Cone Inputs to Receptive Fields in the Parvocellular Pathway: Random Wiring with Functional Bias
}

\author{
Péter Buzás, ${ }^{1,2}$ Esther M. Blessing, ${ }^{1,2}$ Brett A. Szmajda, ${ }^{1,2}$ and Paul R. Martin ${ }^{1,2}$ \\ ${ }^{1}$ National Vision Research Institute of Australia, Carlton, Victoria 3053, Australia, and 2Department of Optometry and Vision Sciences, The University of \\ Melbourne, Parkville, Victoria 3052, Australia
}

\begin{abstract}
Many of the parvocellular pathway (PC) cells in primates show red-green spectral selectivity (cone opponency), but PC ganglion cells in the retina show no anatomical signs of cone selectivity. Here we asked whether responses of PC cells are compatible with "random wiring" of cone inputs. We measured long-wavelength-sensitive $(\mathrm{L})$ and medium-wavelength-sensitive (M) cone inputs to PC receptive fields in the dorsal lateral geniculate of marmosets, using discrete stimuli (apertures and annuli) to achieve functional segregation of center and surround. Receptive fields between the fovea and $30^{\circ}$ eccentricity were measured.

We show that, in opponent PC cells, the center is dominated by one ( $\mathrm{L}$ or M) cone type, with normally $<20 \%$ contribution from the other cone type (high "cone purity"), whereas non-opponent cells have mixed L and M cone inputs to the receptive field center. Furthermore, opponent response strength depends on the overall segregation of $\mathrm{L}$ and $\mathrm{M}$ cone inputs to center and surround rather than exclusive input from one cone type to either region. These data are consistent with random wiring. The majority of PC cells in both foveal $\left(<8^{\circ}\right)$ and peripheral retina nevertheless show opponent responses. This arises because cone purity in the receptive field surround is at least as high as in the center, and the surround in nearly all opponent PC cells is dominated by the opposite cone type to that which dominates the center. These functional biases increase the proportion of opponent PC cells, but their anatomical basis is unclear.
\end{abstract}

Key words: color vision; primate; parvocellular; receptive fields; lateral geniculate nucleus; vision

\section{Introduction}

In trichromatic ("normal color vision") primates, most parvocellular pathway (PC) cells show functional antagonism of inputs from long-wavelength-sensitive (L) and medium-wavelengthsensitive (M) cones to the receptive field (DeMonasterio et al., 1975; Derrington et al., 1984; Lee et al., 1987, 1990; Yeh et al., 1995a; Benardete and Kaplan, 1999). Most foveal PC cells derive input from a single $\mathrm{L}$ or $\mathrm{M}$ cone via a single midget bipolar cell (Kolb and Dekorver, 1991; Calkins et al., 1994; Jusuf et al., 2006a) and thus should get a dominant functional input to the receptive field center from a single cone type. Under the "random wiring" hypothesis (Mollon et al., 1984; Shapley and Perry, 1986; Lennie et al., 1991), this one-to-one connectivity is the dominant source of spectral bias in PC fields and thus produces the afferent signals serving red-green color vision. Consistently, anatomical analyses of the foveal retina have so far revealed no other sign of selective wiring for L and M cones (Wässle et al., 1989; Calkins and Sterling, 1996, 1999; Jusuf et al., 2006a).

The random wiring hypothesis predicts that, in peripheral retina, there will be mixing of input from $\mathrm{L}$ and $\mathrm{M}$ cones to the

Received April 4, 2006; revised Sept. 11, 2006; accepted Sept. 21, 2006.

This work was supported by Australian National Health and Medical Research Council Grant 253621 and Australian Research Council Grant A00104053. We thank A. Lara and D. Matin for technical assistance, T. FitzGibbon and P. Jusuf for assistance with recordings, J. Forte, U. Grünert, S. Solomon, and T. R. Vidyasagar for helpful comments, and U. Grünert, P. Jusuf, and S. C. S. Lee for the drawing shown in Figure 4.

Correspondence should be addressed to Paul R. Martin, National Vision Research Institute of Australia, Corner of Keppel and Cardigan Streets, Carlton, Victoria 3053, Australia. E-mail: prmartin@unimelb.edu.au.

DOI:10.1523/JNEUROSCI.3237-06.2006

Copyright $\odot 2006$ Society for Neuroscience $\quad 0270-6474 / 06 / 2611148-14 \$ 15.00 / 0$ receptive field center (Lennie et al., 1991; Mullen and Kingdom, 1996; Calkins and Sterling, 1999; Diller et al., 2004), and this is supported by anatomical and physiological observations (Diller et al., 2004; Jusuf et al., 2006b) (but see Solomon et al., 2005). It is therefore unclear why many PC cells in peripheral retina show cone-opponent signals (DeMonasterio and Gouras, 1975; Solomon et al., 2005). Furthermore, the question whether the surround of PC cells shows mixed input from $\mathrm{L}$ and $\mathrm{M}$ cones has not been resolved conclusively (Smith et al., 1992; Lankheet et al., 1998b; Lee et al., 1998; Reid and Shapley, 2002). Finally, the fundamental question of how chromatic sensitivity depends on functional segregation of $\mathrm{L}$ and $\mathrm{M}$ cone inputs has not been answered definitively.

Cone inputs to $\mathrm{PC}$ receptive fields have been measured using spatial- or temporal-frequency modulation (Kaplan et al., 1989; Smith et al., 1992; Yeh et al., 1995b; Lankheet et al., 1998b; Benardete and Kaplan, 1999) or spatially discrete stimuli such as pseudorandom checkerboards and counterphase edges (Lee et al., 1998; Reid and Shapley, 2002). In these methods, the receptive field center and surround are modulated simultaneously. This makes it difficult to measure cone mixing in the surround, because the overall response of the cell is dominated by the center mechanism. Here, we minimized this problem by using annuli to stimulate preferentially the receptive field surround and apertures to stimulate the receptive field center (Westheimer, 1967; Kilavik et al., 2003). We used cone-isolating ("silent substitution") modulation to measure the contribution of $L$ and $M$ cones to center and surround. Our experimental goals were to relate the 
amplitude of cone-opponent responses to the functional weight of cone inputs and to compare the cone-opponent signal in foveal and peripheral retina.

\section{Materials and Methods}

Female marmosets (Callithrix jacchus) were obtained from the Australian National Health and Medical Research Council combined breeding facility. Three trichromatic adult females, carrying the genes for the 543 and $563 \mathrm{~nm}$ opsins [identified by PCR-restriction fragment length polymorphism (Blessing et al., 2004)] were selected for physiological recordings. Animals were anesthetized and prepared for extracellular singleunit recordings using experimental protocols described in detail previously (Blessing et al., 2004). Procedures were approved by institutional Animal Experimentation and Ethics Committee and conform to the Society for Neuroscience policy on the use of animals in neuroscience research. Action potential time series from individual PC cells in the dorsal lateral geniculate nucleus were digitized at $10 \mathrm{kHz}$. Responses were subjected to Fourier analysis. The first harmonic amplitude and phase were used as response measures.

Stimuli were presented on a computer monitor at $80 \mathrm{~Hz}$ frame refresh rate and centered on the receptive field via a gimbaled mirror. Stimulusresponse curves for contrast, aperture, and annulus tuning were recorded using modulation along four color axes: $\mathrm{L}$ and $\mathrm{M}$ cone isolating, isoluminant chromatic $(\mathrm{L}-\mathrm{M})$, and luminance $(\mathrm{L}+\mathrm{M})$. Temporal frequency was $4 \mathrm{~Hz}$. This value was chosen because it yielded robust responses in nearly all PC cells recorded but is low enough to avoid the masking of opponent responses that occurs at higher temporal frequencies (cf. Diller et al., 2004; Solomon et al., 2005). Mean luminance was close to $25 \mathrm{~cd} \cdot \mathrm{m}^{-2}$. Cone-isolating stimuli (calculated by convolution of the monitor phosphor spectra with photoreceptor spectral templates) were confirmed as accurate in separate experiments (Blessing et al., 2004; Forte et al., 2006). Contrast for $\mathrm{L}+\mathrm{M}$ tuning functions was set to evoke close to 25 action potentials (impulses) per second on a nonsaturating region of the contrast-response curve. Contrast gain (impulses $\cdot \mathrm{s}^{-1} \cdot \%^{-1}$ Michelson contrast) was estimated as the initial slope of the best-fit Naka-Rushton function (Croner and Kaplan, 1995; Yeh et al., 1995a). If the response at maximum stimulus contrast was $<10$ impulses/s, we estimated response gain as response amplitude at maximum stimulus contrast $/ 100$. The stimuli were generated using only the red and green monitor phosphors. Cells were also tested for signs of functional input from short-wavelength-sensitive (S) cones as described previously (Forte et al., 2006). None of the PC cells showed significant input from $S$ cones.

The maximum Michelson cone contrast was close to $36 \%$ for $\mathrm{L}$ and $\mathrm{M}$ cone-isolating stimuli; the cone contrast for the chromatic $(\mathrm{L}-\mathrm{M})$ stimulus was adjusted to be half this value for each cone class. Accordingly, we categorized cells as non-opponent if the gain ratio $(\mathrm{L}-\mathrm{M})$ / $(\mathrm{L}+\mathrm{M})$ for large-field stimuli was $\leq 0.36$ (that is, the sum of $\mathrm{L}$ and $\mathrm{M}$ cone contrasts) or if the maximum response to the $\mathrm{L}-\mathrm{M}$ stimulus was below 10 impulses/s. Thus, an opponent cell response to $\mathrm{L}-\mathrm{M}$ modulation is greater than the response to $\mathrm{L}+\mathrm{M}$ modulation at the same cone contrast. However, the reader should note that these criteria do not imply the existence of discrete populations of PC cells, and the results show a continuum of response properties on all stimulus dimensions that we measured. Our purpose here was to relate our study to categorizations made by others and to the qualitative pattern of responses elicited by hand-held stimuli.

\section{Results}

\section{Predictions of the random wiring hypothesis}

The random wiring hypothesis is illustrated in Figure 1, which shows how a PC receptive field could draw functional inputs from a trichromatic cone mosaic in the perifoveal retina. Lennie et al. (1991) showed that red-green opponent responses of foveal PC cells could be explained by functional input from a single L or $\mathrm{M}$ receptor to the receptive field excitatory mechanism, opposed by a Gaussian-weighted mixture of $\mathrm{L}$ and $\mathrm{M}$ cones in the inhibitory mechanism. A simple elaboration of this model (Mullen and
$A$

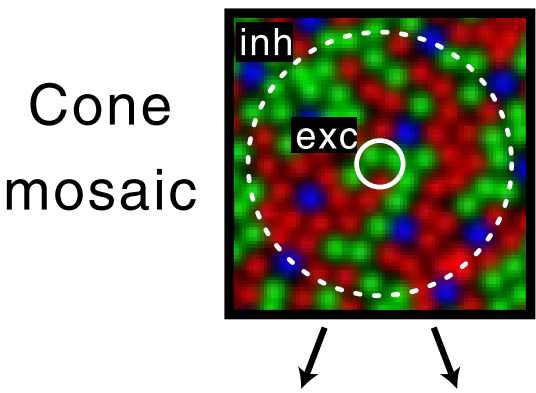

$B$
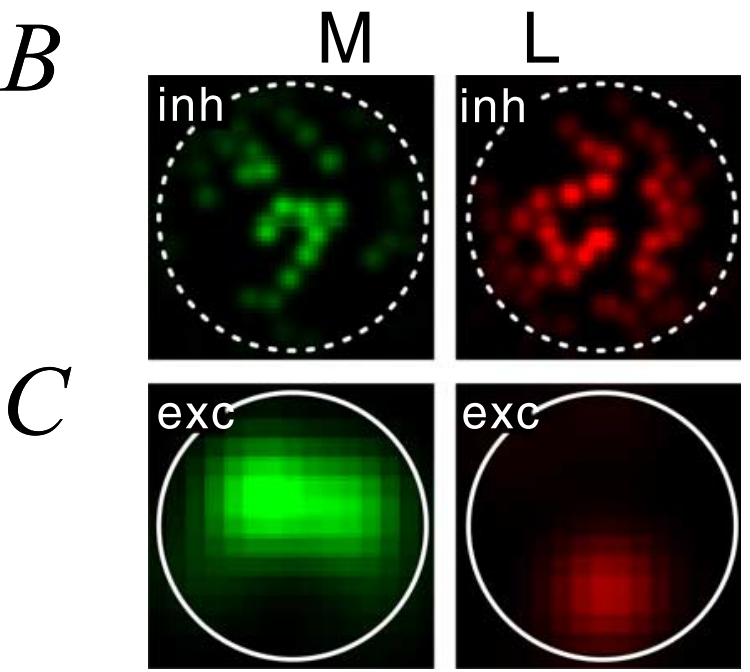

$D$

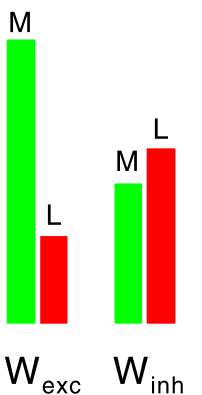

Figure 1. Schematic representation of $\mathrm{PC}$ receptive fields. $A$, Simulated patch of cone mosaic with randomly assigned $L$ and $M$ cones. White circles indicate the receptive field subunits: excitatory center (exc; solid line) and inhibitory surround (inh; dashed line) at 1 SD of the Gaussian weighting functions. $\boldsymbol{B}$, Illustration of $\mathrm{L}$ and $\mathrm{M}$ cone contributions to surround inhibition (inh). The inhibitory surround receives approximately equal $L$ and $M$ input. $C$, Enlargement of the excitatory (exc) center part of the receptive field from $A$, showing strong contribution of $M$ cones and weaker contribution of $L$ cones. $D$, The weight of $L$ and $M$ cone inputs to center and surround can be calculated by integration of Gaussian weighting functions $\left(G_{\text {exc }} G_{\text {inh }}\right)$. The left shows schematically the Gaussian subunits (solid lines, excitation; dashed lines, inhibition). The right shows schematically the integrated $L$ and $M$ cone contributions to center excitation ( $\left.W_{\text {exc }}\right)$ and surround inhibition $\left(\mathrm{W}_{\text {inh }}\right)$.

Kingdom, 1996) can be used to illustrate the effect of convergent input from $\mathrm{L}$ and $\mathrm{M}$ cones to both center and surround. Here (Fig. 1), the cone inputs are expressed as a sum of four Gaussianweighted components (Rodieck and Stone, 1965; Derrington and Lennie, 1984). Each "pair” of Gaussians, (L and M excitation) and ( $\mathrm{L}$ and $\mathrm{M}$ inhibition), is set to have the same width, but the $\mathrm{L}$ and $\mathrm{M}$ components of each pair can have different amplitudes. The center draws from a smaller number of cones than the surround, and thus the relative weight of $\mathrm{L}$ and $\mathrm{M}$ cone inputs ["cone purity" (Mullen and Kingdom, 1996)] shows greater imbalance 
in the center than in the surround. In the example shown, the excitatory (center) mechanism is dominated by $\mathrm{M}$ cones (Fig. $1 C$ ), whereas the inhibitory (surround) mechanism gets mixed $\mathrm{L} / \mathrm{M}$ cone input close to the average $\mathrm{L} / \mathrm{M}$ cone ratio (Fig. $1 \mathrm{~B}$ ). With increasing size of the receptive field, the degree of asymmetry in center and surround weights ["opponent purity" (Mullen and Kingdom, 1996)] is predicted to fall because the center draws from larger numbers of cones. These two predictions of the random wiring hypothesis (low cone purity in the surround at all eccentricities, and decreasing center cone purity with increasing eccentricity) can be tested using stimuli that differentially activate the center and surround but are insensitive to the exact position of each $\mathrm{M}$ or $\mathrm{L}$ cone in the mosaic. We show below that these requirements are met by temporal modulation of apertures and annuli and that both the center and surround of the majority of PC cells shows high cone purity.

Comparison of responses in foveal and peripheral visual field Complete datasets were obtained for 32 PC cells. A complete dataset comprised triplicate measurement of responses to 12 aperture ("spot") and 13 annulus ("donut") sizes on $\mathrm{L}-\mathrm{M}, \mathrm{L}+\mathrm{M}$, $\mathrm{L}$-isolating, and $\mathrm{M}$-isolating cone axes, together with spatial frequency and contrast tuning curves, yielding a total of $\sim 360$ measurement points for each cell. Data from five additional cells with incomplete aperture and annulus tuning data and two cells with incomplete spatial frequency tuning data were consistent with the complete datasets and are included when possible in the results reported below.

Figure 2 shows responses to chromatic $(\mathrm{L}-\mathrm{M})$ and luminance $(\mathrm{L}+\mathrm{M})$ modulation for opponent $\mathrm{PC}$ cells recorded with receptive fields near the fovea (Fig. $2 \mathrm{~A}$ ) and near $15^{\circ}$ eccentricity (Fig. $2 B$ ) and one non-opponent PC cell (Fig. 2C) recorded near $15^{\circ}$ visual field eccentricity. The pattern of responses is consistent with that reported previously for foveal and peripheral PC ganglion cells in macaque (Solomon et al., 2005) and foveal PC cells in marmosets (Yeh et al., 1995a; Blessing et al., 2004). All cells show mildly saturating contrast-response relationship for $\mathrm{L}+\mathrm{M}$ modulation, and the opponent cells additionally display vigorous responses to $\mathrm{L}-\mathrm{M}$ modulation. Figure $2 \mathrm{D}$ shows $\mathrm{L}-\mathrm{M}$ and $\mathrm{L}+$ $\mathrm{M}$ gain for all PC cells recorded, together with the criterion $(\mathrm{L}-$ $\mathrm{M}) /(\mathrm{L}+\mathrm{M})$ gain ratio (Fig. $2 \mathrm{D}$, dashed line).

Figure 3 shows that the increase in receptive field center radius with eccentricity (Fig. $3 A$ ) is not associated with a large decrease in the proportion of opponent PC cells (Fig. $3 B$ ). Mean center radius for $\mathrm{PC}$ cells recorded above $8^{\circ}$ eccentricity $\left(0.127 \pm 0.042^{\circ}\right.$, mean $\pm \mathrm{SD} ; n=21$ ) was approximately three times greater than for PC cells recorded below $8^{\circ}\left(0.039 \pm 0.015^{\circ}\right.$, mean $\pm \mathrm{SD} ; n=$ 13; $p<0.01$, unpaired Wilcoxon's test), but the proportion of opponent cells recorded above $8^{\circ}(13$ of $23,56.5 \%)$ is only slightly lower than the proportion recorded below $8^{\circ}$ (10 of $\left.14,71 \%\right)$. Because we only classified cells as opponent if the $\mathrm{L}-\mathrm{M}$ gain was $>0.1$ impulses $\cdot \mathrm{s}^{-1} \cdot \%^{-1}$, there is some overlap of opponent and non-opponent cells near the equal cone contrast ratio of 0.36 (Fig. 3B). However, even under these conservative criteria, it is clear that chromatic opponent PC cells are not restricted to the central visual field. The log gain ratio for cells recorded below $8^{\circ}$ eccentricity $(0.005 \pm 0.432$, mean $\pm \mathrm{SD} ; n=21)$ is slightly greater than for PC cells recorded above $8^{\circ}(-0.220 \pm 0.480$, mean $\pm \mathrm{SD} ; n=23 ; p=0.11$, unpaired Wilcoxon's test). On the basis of these variance measures, a sample of $>40$ cells in each group would be required to detect a decline of $50 \%$ in mean gain ratio with a power of 0.8 (Lenth, 2006). In summary, there is little evidence for a systematic decline in opponency with eccentricity in the sample of PC cells we measured.

The known anatomical properties of the marmoset retina allow the expected convergence of cone photoreceptors to the receptive field center of extrafoveal PC cells to be estimated. Figure $4 A$ shows a drawing of a midget ganglion cell at $13^{\circ}$ eccentricity (Jusuf et al., 2006b). The cell drawing is superimposed on a drawing of the cone pedicle mosaic close to this eccentricity (Fig. $4 \mathrm{~A}$, gray patches). The average excitatory center radius of PC cells ( 1 $\mathrm{SD}$ of the Gaussian weighting function) at this position is also indicated (Fig. $4 \mathrm{~A}$, red circle). This shows first that the physiological estimate of center radius of PC cells is consistent with the dendritic field radius of midget cells in peripheral marmoset retina, and second that the peripheral receptive fields would be expected to receive convergent input from $>15$ cones.

Goodchild et al. (1996) showed that, in extrafoveal primate retina, the dendritic field area of PC cells increases in an approximately inverse relationship to cone photoreceptor density. This allows a simple (albeit indirect) estimate of convergence to each PC cell in our dataset. Figure $4 B$ shows data points replotted from Goodchild et al. (1996), their Figure 13. The average midget ganglion cell dendritic field area (square millimeters) divided by the average cone photoreceptor density (cones per square millimeters) is shown at a set of eccentricities above $5^{\circ}$. These data are well fit by linear regression $Y=-22.1281+3.3488 \times X$, where $Y$ is number of cones per cell, and $X$ is eccentricity in degrees $\left(r^{2}=\right.$ 0.99 ) (Fig. $4 B$, solid line). The convergence measured for the cell illustrated in $A$ (Fig. $4 B$, blue asterisk) is consistent with this prediction. The linear regression was applied to the eccentricity of extrafoveal $\left(>5^{\circ}\right)$ PC cells in our dataset, as shown in Figure $4 C$. For simplicity, we did not incorporate our measured variation in receptive field center size in this estimation. Convergence for cells below $5^{\circ}$ eccentricity was set to 1 , corresponding to the one-to-one connections of foveal midget ganglion cells (Kolb and Dekorver, 1991; Calkins et al., 1994; Jusuf et al., 2006a). It can be seen that the majority of PC cells is expected to receive convergent input from cone photoreceptors to the receptive field center. We conclude that the presence of chromatic opponent responses in marmoset PC cells is not dependent on one-to-one connectivity of the foveal midget pathway. We next asked how the cone inputs to PC pathway cells are organized to produce opponent responses, by a spatiochromatic analysis of the receptive field.

\section{Spatiochromatic analysis of the receptive field}

In the following, the reader should keep in mind a subtle distinction between the receptive field regions of a PC cell and the physiological mechanisms that give rise to these regions. The receptive field surround is a more-or-less annular-shaped inhibitory region, which is concentric with an excitatory center region (Kuffler, 1953; Wiesel and Hubel, 1966). However, as illustrated in Figures 1 and $5 A$, the process that gives rise to these regions is well described as a combination of a (weak but spatially broad) zone of inhibition, which overlaps with a (powerful but spatially restricted) zone of excitation (Rodieck and Stone, 1965; Dreher et al., 1976; Derrington and Lennie, 1984). Here we use the terms center and surround to refer to discrete regions of the receptive field and excitation and inhibition to refer to the corresponding mechanisms.

It is well known that the difference-of-Gaussians (DOG) receptive field model (Rodieck and Stone, 1965; Enroth-Cugell and Robson, 1966; Frishman et al., 1987) can describe the responses of PC cells to drifting sinusoid luminance gratings (Derrington and Lennie, 1984; Croner and Kaplan, 1995; Kremers and Weiss, 
A
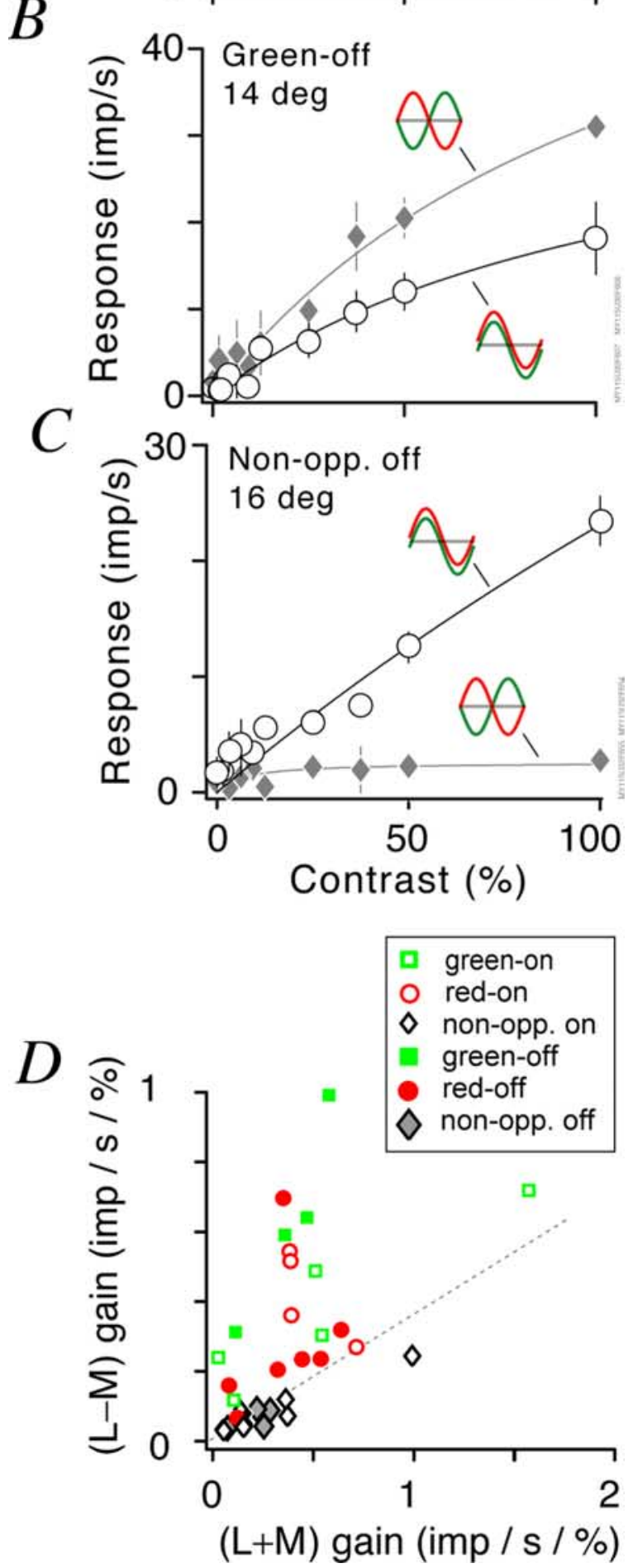

$A$

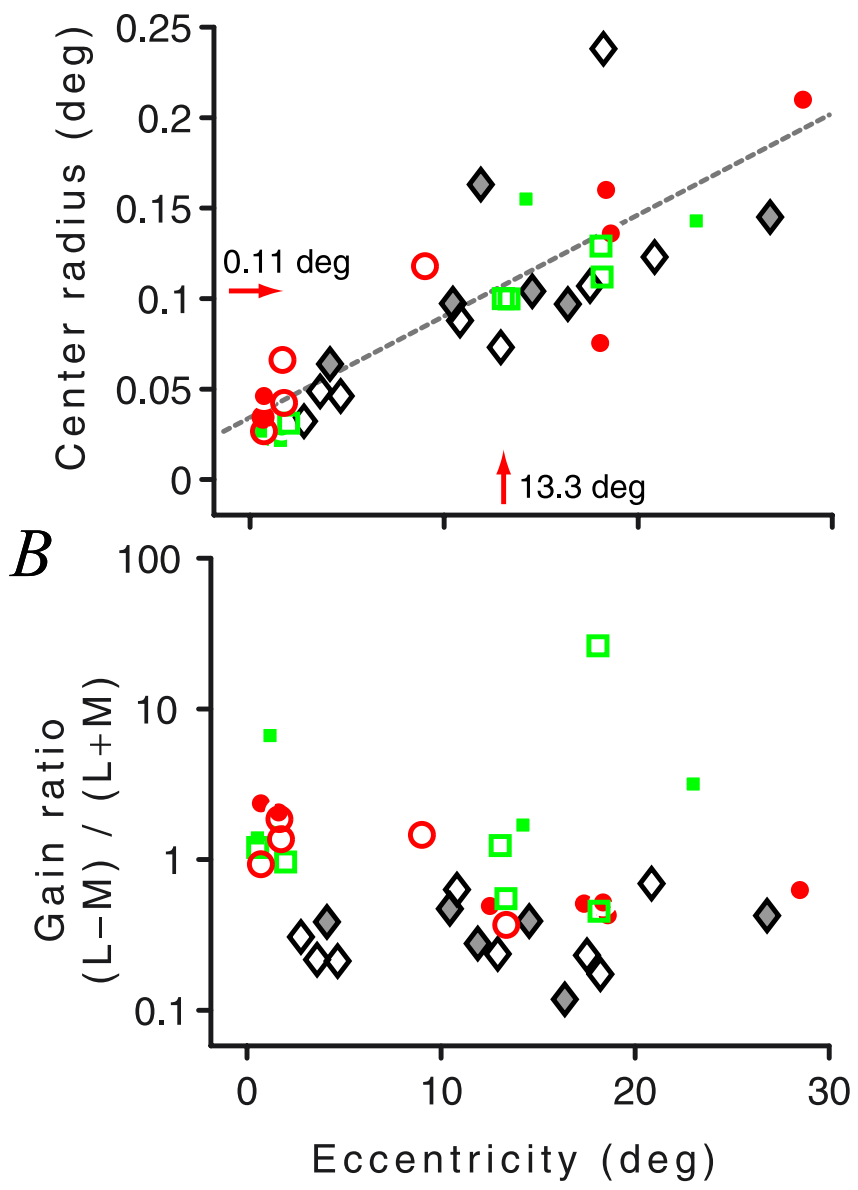

Figure 3. Eccentricity dependence of chromatic and spatial responses. $A$, Center radius of $\mathrm{PC}$ cells calculated from DOG fit to spatial frequency tuning curves obtained with drifting luminance gratings. Dashed line shows linear regression: $Y=0.0314+0.0056 X\left(r^{2}=0.7020\right)$, where $Y$ is center radius, and $X$ is receptive field eccentricity. The small arrows show the expected center radius at the eccentricity used to estimate cone convergence in Figure $4 A$. $\boldsymbol{B}$, Ratio of chromatic to luminance response gains. Note that there is no clear evidence for a decline in average chromatic sensitivity with increasing eccentricity.

1997; White et al., 2001). Kilavik et al. (2003) and Kremers et al. (2004) showed that this model also can account for PC cell responses to counterphase luminance modulation, in apertures or annuli that are centered on the receptive field. We therefore explored the potential of such spatially discrete stimuli to stimulate selectively the center and surround and thus enable measurement of $\mathrm{L}$ and $\mathrm{M}$ cone contributions to each.

A prerequisite for such measurements is that the stimulus remains concentric with the receptive field, so it is important to

$\leftarrow$

Figure 2. Relative sensitivity to luminance and chromatic variation in $\mathrm{PC}$ cells. Stimulus was a spatially uniform $4^{\circ}$ field modulated at $4 \mathrm{~Hz}$. $A, B$, Green-0ff cells with foveal $\left(1.6^{\circ}\right)$ and peripheral $\left(16^{\circ}\right)$ receptive fields. Responses to $\mathrm{L}-\mathrm{M}$ (red-green chromatic) modulation (diamonds, gray line) exceed responses to $L+M$ (yellow-black luminance) modulation (circles, black lines) at all stimulus contrasts. The peak cone contrast for the chromatic stimulus was close to $18 \%$ for each ( $L$ and $M$ ) cone mechanism. Error bars show SDs; small error bars may be obscured by the marker symbols. Solid lines show Naka-Rushton model functions. Contrast gain was defined as the initial slope of these curves. $C$, Non-opponent Off cell, receptive field eccentricity $16^{\circ}$. Responses to luminance modulation exceed responses to chromatic modulation. $D$, Scatter plot of $(L-M)$ versus $(L+M)$ contrast gain. Dashed line shows criterion cone contrast (36\%) for classifying opponent cells. 


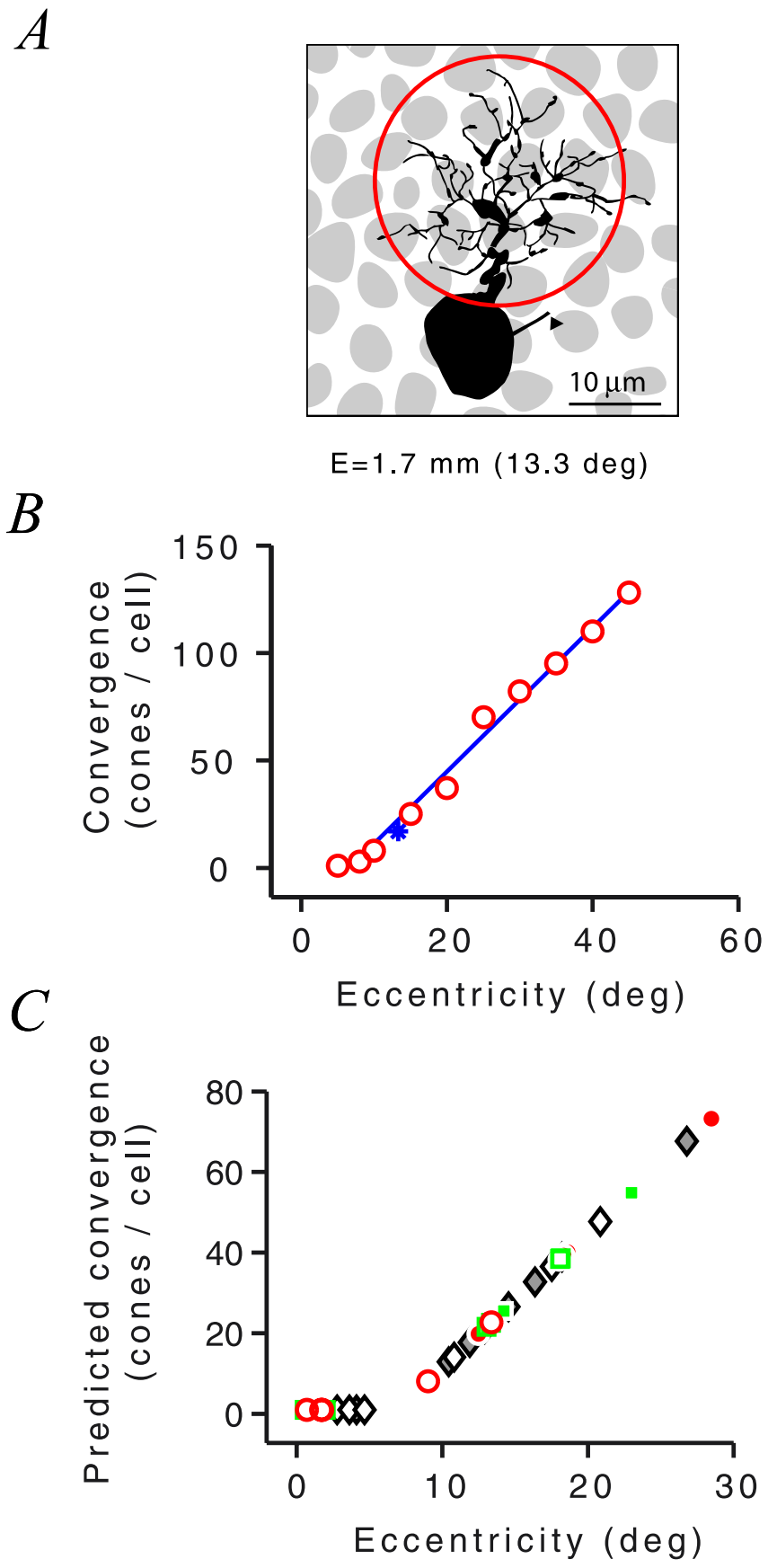

Figure 4. A, Anatomical estimate of cone convergence to $\mathrm{PC}$ cells in mid-peripheral marmoset retina. The black silhouette shows a midget ganglion cell labeled after injections in the $P C$ layers (data from the study by Jusuf et al., 2006). The gray patches show the mosaic of cone photoreceptor pedicles at the same retinal eccentricity (data from the study by Lee et al., 2005). The red circle shows at the same scale the predicted PC center radius (1 SD of the Gaussian weighting function) from Figure $3 A$. The anatomical and physiological predictions agree that the center mechanism should draw convergent input from at least 15 cones at this eccentricity. $B$, Predicted numerical convergence of cone photoreceptors to $\mathrm{PC}$ cells. Data points (from the study of Goodchild et al., 1996) show the average midget ganglion cell dendritic field area (square millimeters) divided by the average cone photoreceptor density (cones per square millimeter) at a set of eccentricities above $5^{\circ}$. Solid line shows linear regression: $Y=$ $-22.1281+3.3488 \times X$, where $Y$ is the number of cones per cell, and $X$ is eccentricity in degrees. Blue asterisk shows convergence measured for the cell shown in $A$. C, Predicted cone convergence to $P C$ cells in our dataset, obtained using the regression line from $\boldsymbol{B}$. Convergence for cells below $5^{\circ}$ eccentricity was set to 1 , corresponding to the one-to-one connections of foveal midget ganglion cells.
$A$

$B$
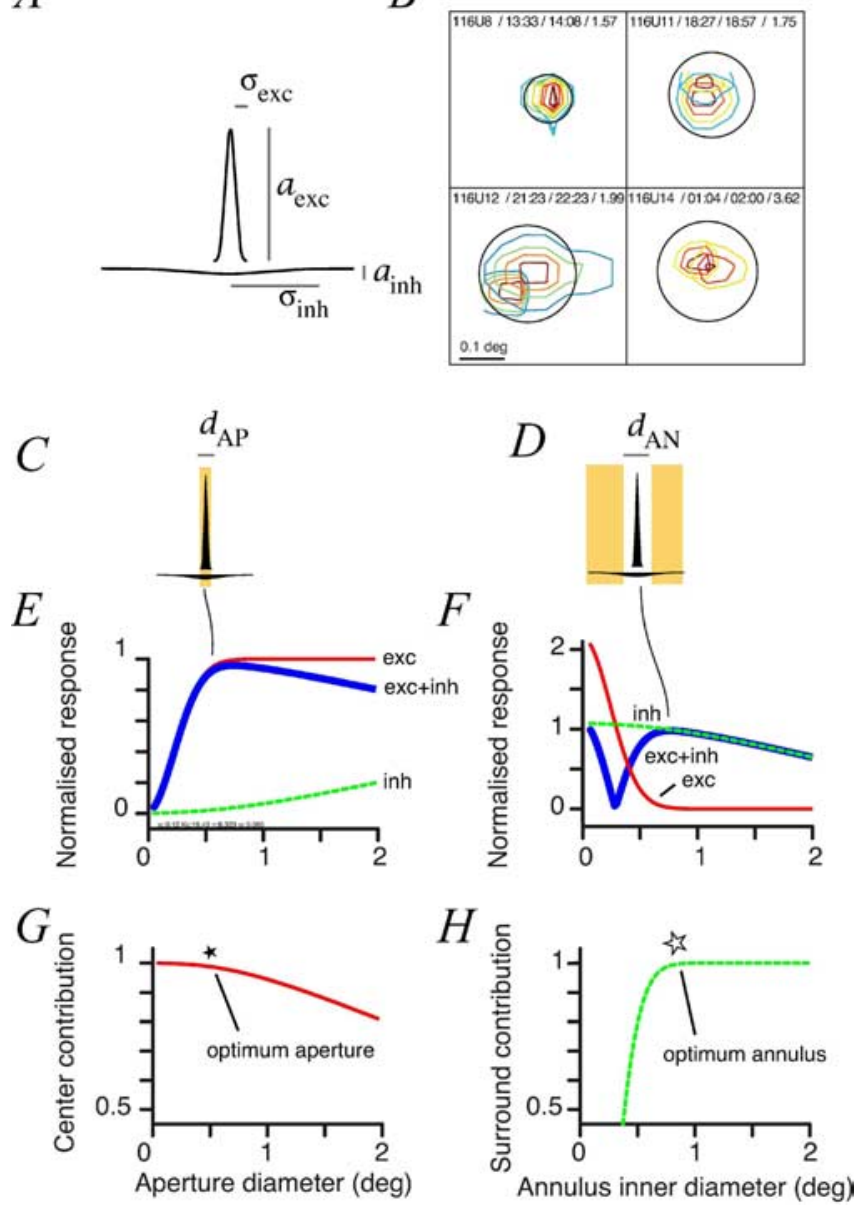

Figure 5. Functional segregation of excitatory and inhibitory mechanisms. $A$, Sketch of the difference-of-Gaussians receptive field model, showing the relative size $(\sigma)$ and amplitude $(a)$ of the excitatory center $\left(\sigma_{\text {exc }} a_{\text {exc }}\right)$ and inhibitory surround $\left(\sigma_{\text {inh }}, a_{\text {inh }}\right)$ receptive field components. The average values obtained from our sample of peripheral $\mathrm{PC}$ cells were used to make this sketch: width ratio $\left(\sigma_{\mathrm{exc}} / \sigma_{\text {inh }}\right)=0.12$; sensitivity ratio $\left(a_{\text {exc }} / a_{\text {inh }}\right)=16.7$. B C Centering accuracy of aperture and annular stimuli. In each subpanel, the two sets of colored contours show isoresponse contours obtained from responses to narrow flashing bars stepped across the receptive field center, before and after data acquisition. The key above each subpanel shows a cell identification code, the acquisition time for each contour set, and receptive field eccentricity. Black circles show the size of the center-optimized aperture for each cell. Note that there is substantial overlap of the isoresponse contours, indicating stability of eye position, and that drifts in position are smaller than the size of the center-optimized aperture. $C, D$, Sketches to illustrate the aperture diameter $\left(d_{\mathrm{AP}}\right)$ and annulus inner diameter $\left(d_{\mathrm{AN}}\right)$ in relation to the receptive field. Curved lines connect each sketch to the appropriate position on the aperture and annulus tuning curves. $\boldsymbol{E}, \boldsymbol{F}$, Predicted response amplitude of the difference-of-Gaussians model to apertures and annuli. Narrow solid line, Excitatory center mechanism (exc). Narrow dashed line, Inhibitory surround mechanism (inh). G, Proportional center contribution to cell response as a function of aperture diameter. $\boldsymbol{H}$, Proportional surround contribution to cell response as a function of annulus inner diameter. Stars in $\boldsymbol{G}$ and $\boldsymbol{H}$ indicate the size of center-optimized aperture $(\boldsymbol{G})$ and surround-optimized annulus $(\boldsymbol{H})$.

ensure that drifts in eye position do not affect the recordings (Forte et al., 2002). Accurate centering of the stimulus on the receptive field was confirmed before and (in nearly all cases) after data collection, by monitoring the position of maximal response to a small ( $<0.05^{\circ}$ radius) flashed spot. On rare occasions, drifts in eye position became evident during or after data collection, because such drifts caused high response variability for small stimuli and characteristic changes in the shape of annulus tuning curves. These data were discarded.

For a subset of cells $(n=7)$, we also quantified eye stability by 
mapping the spatial response profile for temporal square-wave flickered $\left(4 \mathrm{~Hz}\right.$ ) horizontal and vertical bar stimuli (length, $8^{\circ}$; width, $\left.0.05-0.2^{\circ}\right)$. Figure $5 B$ shows excitatory response profiles of four sequentially measured PC cells. Two sets of isoresponse contours are shown for each cell; these measurements were taken before and after data collection. The contours show a high degree of overlap, indicating that eye position has remained stable. The mean receptive field drift over this period (between 0.5 and $2 \mathrm{~h}$ ) was $0.078 \pm 0.052^{\circ}$ (mean $\pm \mathrm{SD} ; n=7$ ), which is close to the diameter of foveal receptive field centers (compare Figs. $3 A, 5 B$ ). In summary, we found that, with careful monitoring, the position of small stimuli can be reliably centered on the receptive field of PC cells for periods of at least $2 \mathrm{~h}$. The filled circles in Figure $5 B$ show the diameter of the aperture stimulus used to stimulate preferentially the receptive excitatory mechanism. This stimulus was normally set to be slightly larger than the excitatory field. The following analysis shows that this configuration gives a high degree of functional isolation yet minimizes the effects of eye drift, especially with foveal receptive fields (Forte et al., 2002).

Figure 5, $C$ and $D$, shows "side-view" sketches of aperture and annulus stimuli in relation to the difference-of-Gaussians receptive field model. The responses of the model to these stimuli were calculated as follows:

$$
R=R_{\text {exc }}-R_{\text {inh }},
$$

where $R$ is the response modulation amplitude of the cell, and $R_{\text {exc }}$ and $R_{\text {inh }}$ are the response amplitudes of the excitatory (center) and inhibitory (surround) subunits, respectively. The response of each subunit is calculated as the integral of a twodimensional Gaussian under the stimulus shape (aperture or annulus) following Kilavik et al. (2003). For an aperture stimulus of radius $r_{\mathrm{AP}}$,

$$
R_{i}=\frac{360 a_{i} \sigma_{i}}{\sqrt{2 \pi}}\left(1-e^{-\frac{r_{\mathrm{AP}}^{2}}{2 \sigma_{i}^{2}}}\right),
$$

where $a_{i}$ is the subunit sensitivity (in impulses $\cdot \mathrm{s}^{-1} \cdot$ degrees $^{-2}$ ), and $\sigma_{i}$ is the standard deviation of the Gaussian (used as a measure of subunit radius) for subunits $i \epsilon$ (exc; inh).

For annular stimuli, we assumed that the outer diameter was sufficient to cover the entire receptive field. Using this simplification, the response to an annulus of inner radius $r_{\mathrm{AN}}$ is modeled (using the notation of Eq. 2) as follows:

$$
R_{i}=\frac{360 a_{i} \sigma_{i}}{\sqrt{2 \pi}} e^{-\frac{r_{\mathrm{AN}}^{2}}{2 \sigma_{i}^{2}}} .
$$

The curves in Figure 5, $E$ and $F$, shows the predicted responses of each subunit and the cell for aperture (Fig. $5 E$ ) and annulus (Fig. $5 F$ ) stimuli. Responses are normalized to the maximum cell response. These predictions are based on the average receptive field parameters we obtained (Fig. $3 A$ ) for our sample of receptive fields above $8^{\circ}$ eccentricity $(n=17)$ : center radius $\left(\sigma_{\text {exc }}\right)=0.12^{\circ}$; surround radius $\left(\sigma_{\text {inh }}\right)=1.00^{\circ}$; and sensitivity ratio $\left(a_{\text {exc }} / a_{\text {inh }}\right)=$ 16.7. With increasing aperture diameter, the cell response (excinh) rises sharply as the center is recruited and then falls gradually as the surround contribution increases more rapidly than the center contribution. Consistently, as annulus inner diameter increases (Fig. 5F), the dominant drive from the receptive field center falls rapidly until it is balanced by the inhibitory subunit to yield a response minimum. The inhibitory mechanism dominates the cell response for annuli with larger inner diameters. Thus, although both the excitatory and inhibitory mechanisms contribute to the cell response for all stimuli, the relative contribution of these mechanisms varies dramatically with stimulus spatial configuration.

Figure $5 G$ shows the proportional contribution of the center mechanism to the cell response as a function of aperture diameter. Over the range of small apertures in which cell response amplitude is rising, the surround contribution is negligible, because the surround sensitivity is much lower than that of the center. An aperture of close to $0.5^{\circ}$ diameter thus produces highly selective activation of the excitatory mechanism. In the same way, annuli with inner diameter close to $0.75^{\circ}$ (Fig. $5 \mathrm{H}$ ) can be used to activate selectively the inhibitory mechanism (although at a lower absolute cell response amplitude; Eq. 3). We refer to these stimuli as "center-optimized aperture" (Fig. 5G, filled star) and "surround-optimized annulus" (Fig. $5 H$, open star) to indicate this functional segregation.

Figure 6 shows responses of a PC cell recorded at $17.7^{\circ}$ eccentricity to illustrate how center-optimized and surroundoptimized stimuli were determined. This cell, which has a relatively strong inhibitory surround (Table 1), illustrates the key features of our measurements. The spatial configuration of the stimulus is sketched in Figure 6A. As expected (Kilavik et al., 2003), response amplitude for luminance $(\mathrm{L}+\mathrm{M})$ modulation is captured well by the DOG model (Fig. 6B, solid lines). The response phase for aperture tuning is dominated by the center mechanism (Fig. 6C, left), whereas there is an abrupt phase shift of $\sim 180^{\circ}$ at the amplitude null point (Fig. $6 C$, right) on the annulus tuning curve. This result conforms nicely with the predictions shown in Figure 5F: the dominant drive to the cell response shifts from excitatory (at small inner diameters) to inhibitory (at large inner diameters).

The tuning curves for chromatic modulation (Fig. 6D) support previous evidence that chromatic opponent responses in parvocellular cells are enhanced by synergy between excitatory and inhibitory mechanisms (Wiesel and Hubel, 1966; DeMonasterio et al., 1975; Dreher et al., 1976; Smith et al., 1992; Lankheet et al., 1998b; Lee et al., 2000; Reid and Shapley, 2002; Saito et al., 2004; Solomon et al., 2005). The peak response amplitude for L $\mathrm{M}$ modulation is approximately half the amplitude of response to $\mathrm{L}+\mathrm{M}$ modulation, but the cone contrast (18\%) is much lower for the $\mathrm{L}-\mathrm{M}$ stimulus than for the $\mathrm{L}+\mathrm{M}$ stimulus (100\%). Thus, $\mathrm{L}-\mathrm{M}$ response gain is $\sim 2.8$ times greater than $\mathrm{L}+\mathrm{M}$ gain. Responses to large $\mathrm{L}-\mathrm{M}$ apertures show little sign of surround attenuation, and response phase is primarily independent of stimulus size (Fig. 6D, filled gray histograms).

The aperture tuning curves obtained using $\mathrm{L}$ and $\mathrm{M}$ coneisolating stimuli (Fig. 6E, F, left) show bandpass characteristic, suggesting that both cone types contribute to both (excitatory and inhibitory) components of the receptive field. There is, however, a functional bias: excitation is dominated by the $M$ cone, whereas inhibition is dominated by the L cone. Accordingly, at all aperture diameters, the response phase for $\mathrm{M}$ cone modulation is dominated by the excitatory mechanism (Fig. 6E, left, histograms), and the annulus tuning curve for $\mathrm{M}$ cone modulation (Fig. $6 E$, right) shows a poorly defined null, with feeble responses to larger annuli. Conversely, the response phase for L cone modulation shows an $\sim 180^{\circ}$ shift between small and large apertures, and for all annuli the effect of L cone modulation is inhibitory (Fig. 6F, histograms). Thus, there is substantial, but incomplete, segregation of $\mathrm{M}$ and $\mathrm{L}$ cone inputs to excitatory and inhibitory inputs to this PC cell. Responses to all stimulus configurations were highly reliable across trials, as indicated by the small error 
bars in Figure 6. This is additional evidence that eye position has remained stable.

In principle, the Gaussian integral analysis described above (Eqs. 2, 3) (Fig. 3) can be used to specify the aperture and annulus diameters that segregate optimally the excitatory and inhibitory inputs. Under the Gaussian model, this segregation can never be complete, because these two mechanisms are overlapping and have infinite spatial extent. Furthermore, PC cell receptive fields show deviation from circular symmetry (Smith et al., 1990; White et al., 2001; Passaglia et al., 2002; Forte et al., 2006), which together with unavoidable small drifts in receptive field position (Fig. 3) and the poorly predictable effects of chromatic aberrations at the stimulus edges (Forte et al., 2006), make the theoretical goal of ideal segregation impossible to achieve in practice. For our analysis, we therefore combined the predictions from the difference-of-Gaussians model with empirical analysis of response phase, to choose a center-optimized aperture and a surroundoptimized annulus for each cell, as follows.

First, the excitatory response phase ("On" or "Off") was measured at the peak of the $\mathrm{L}+\mathrm{M}$ aperture tuning curve (Oncenter cells, $308.4 \pm 7.4^{\circ}$, mean $\pm \mathrm{SD}, n=$ 17 ; Off-center cells, $136.0 \pm 17.3^{\circ}$, mean \pm $\mathrm{SD}, n=17)$. Second, the center-optimized aperture was taken as the aperture closest to the peak of the $\mathrm{L}+\mathrm{M}$ tuning curve, with the additional constraint that the response phase for the cone-isolating ( $\mathrm{M}$ or $\mathrm{L}$ ) conditions was within $90^{\circ}$ of the excitatory response phase (Fig. 6A,C-F, filled stars). Finally, the surround-optimized annulus was taken as the annulus closest to the peak of the $\mathrm{L}+\mathrm{M}$ annulus tuning curve, with the constraint that the response phase for the cone-isolating conditions was greater than $\pm 90^{\circ}$ of the excitatory response phase. The upshot of this process for nearly all PC cells was to leave a "gap" between the outer border of the centeroptimized aperture and the inner border of the surround-optimized annulus. Previous analyses (Derrington et al., 1984; Smith et al., 1992; Lankheet et al., 1998b) show that, in macaques, PC cells combine $\mathrm{L}$ and $\mathrm{M}$ cone inputs linearly at low cone contrasts, so observations made in noncontiguous regions of the receptive field can be reasonably extrapolated to explain cell behavior. Analysis of our data (described below) supports this assumption.

The cone inputs to center and surround were estimated from response amplitude to $\mathrm{L}$ and $\mathrm{M}$ cone-isolating conditions, for these optimized stimuli. In some

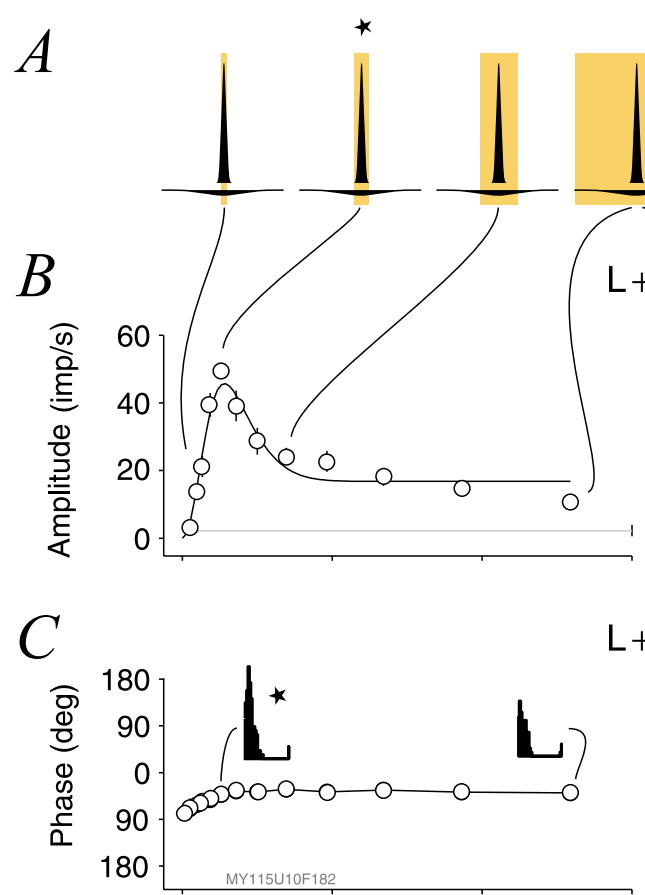

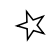

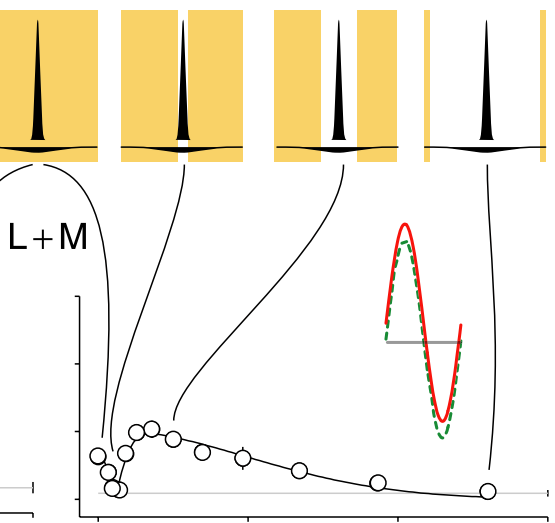

$L+M$

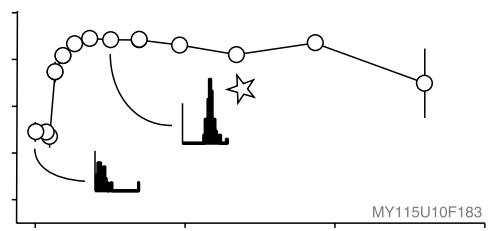

$D$

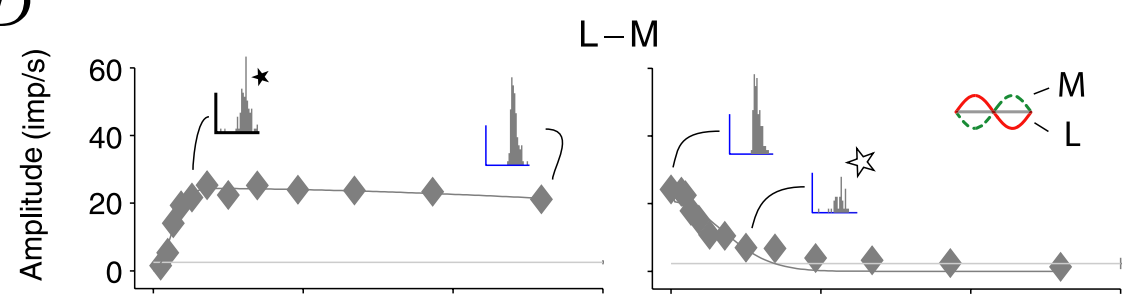

E

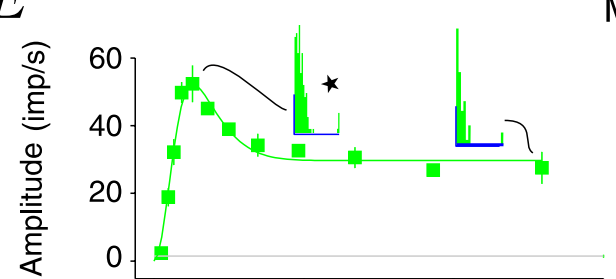

M

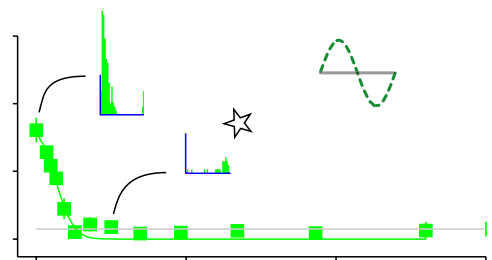

$F$

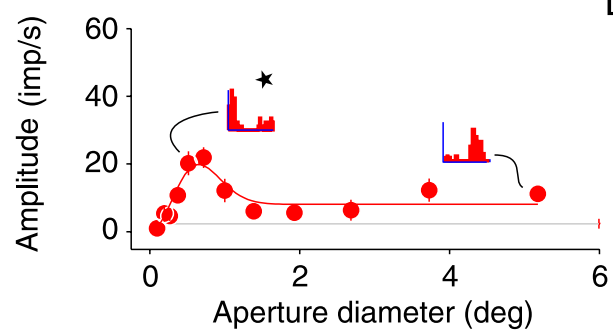

$\mathrm{L}$

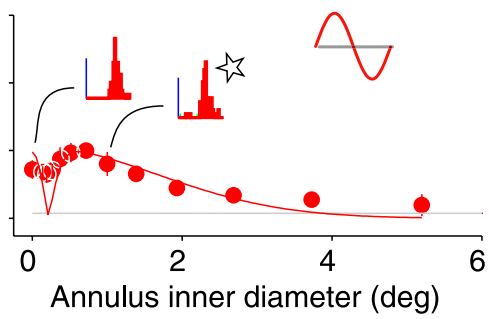

Figure 6. Aperture and annulus tuning for a green- $0 \mathrm{n} P($ cell. Left, Aperture tuning; right, annulus tuning. $\boldsymbol{A}$, Sketches of the receptive field in relation to the stimulus, as in Figure 3. $\boldsymbol{B}, \boldsymbol{C}$, Luminance $(\mathrm{L}+\mathrm{M})$ modulation. Response amplitude (F1) is shown in $\boldsymbol{B}$; response phase is shown in $\boldsymbol{C}$. Aperture tuning curve shows bandpass amplitude characteristic; response phase is dominated by the center mechanism at all apertures. In contrast, annulus tuning for luminance modulation shows an amplitude minimum and phase reversal (inset histograms, $\boldsymbol{C}$ ) close to $0.27^{\circ}$ inner diameter. $\boldsymbol{D}$, Chromatic modulation. Response amplitude shows little sign of center-surround antagonism, and response phase is consistent with synergistic $M$ cone excitation and $L$ cone inhibition (inset histograms). Consistently, responses to cone-isolating stimuli $(\boldsymbol{E}, \boldsymbol{F})$ show that center excitation is dominated by $M$ cones $(\boldsymbol{E})$, whereas the surround is more strongly driven by $\mathrm{L}$ cones $(\boldsymbol{F})$. Response phase is dominated by $M$ excitation at all aperture diameters. A weak inhibitory contribution of $M$ cones is evident at the surround-optimized annulus (open star, $\boldsymbol{E}$ ). Response to $\mathrm{L}$ cone-isolating apertures shows strong center-surround antagonism, and response phase is dominated by $L$ inhibition at all annulus diameters. Error bars on amplitude plots show SDs. Curves show DOG model fits. Horizontal gray lines show F1 amplitude at 0 stimulus contrast. D0G fit parameters are given in Table 1. The phase and approximate amplitude of cone modulation is sketched (insets) for each stimulus condition. 
Table 1. Best fit estimates of the DOG model parameters for the data in Figure 6

\begin{tabular}{llllll}
\hline Stimulus & \multicolumn{5}{c}{} \\
\hline \multirow{2}{*}{ Shape } & Color & $\begin{array}{l}\text { Center sensitivity } \\
\left(a_{c^{\prime}} \text { impulses } \cdot s^{-1} \cdot \text { degrees }^{-2}\right)\end{array}$ & $\begin{array}{l}\text { Center radius } \\
\left(\sigma_{c^{\prime}} \text { degrees }\right)\end{array}$ & $\begin{array}{l}\text { Surround sensitivity } \\
\left(a_{s^{\prime}} \text { impulses } \cdot s^{-1} \cdot \text { degrees }^{-2}\right)\end{array}$ & $\begin{array}{l}\text { Surround radius } \\
\left(\sigma_{s^{\prime}} \text { degrees }\right)\end{array}$ \\
\hline Aperture & $\mathrm{L}+\mathrm{M}$ & 15.42 & 0.13 & 4.94 & 0.30 \\
& $\mathrm{~L}-\mathrm{M}$ & 1.53 & 0.11 & 0.03 & 5.04 \\
& $\mathrm{~L}$ & 11.18 & 0.20 & 10.27 & 0.22 \\
& $\mathrm{M}$ & 4.44 & 0.11 & 0.93 & 0.29 \\
Annulus & $\mathrm{L}+\mathrm{M}$ & 8.71 & 0.11 & 0.60 & 0.98 \\
& $\mathrm{~L}-\mathrm{M}$ & n.d. & n.d. & n.d. & n.d. \\
& $\mathrm{L}$ & n.d. & n.d. & n.d. & n.d. \\
& $\mathrm{M}$ & 494.4 & $8.8 \times 10^{-4}$ & 1.71 & 0.12 \\
\hline
\end{tabular}

n.d., Not determined.

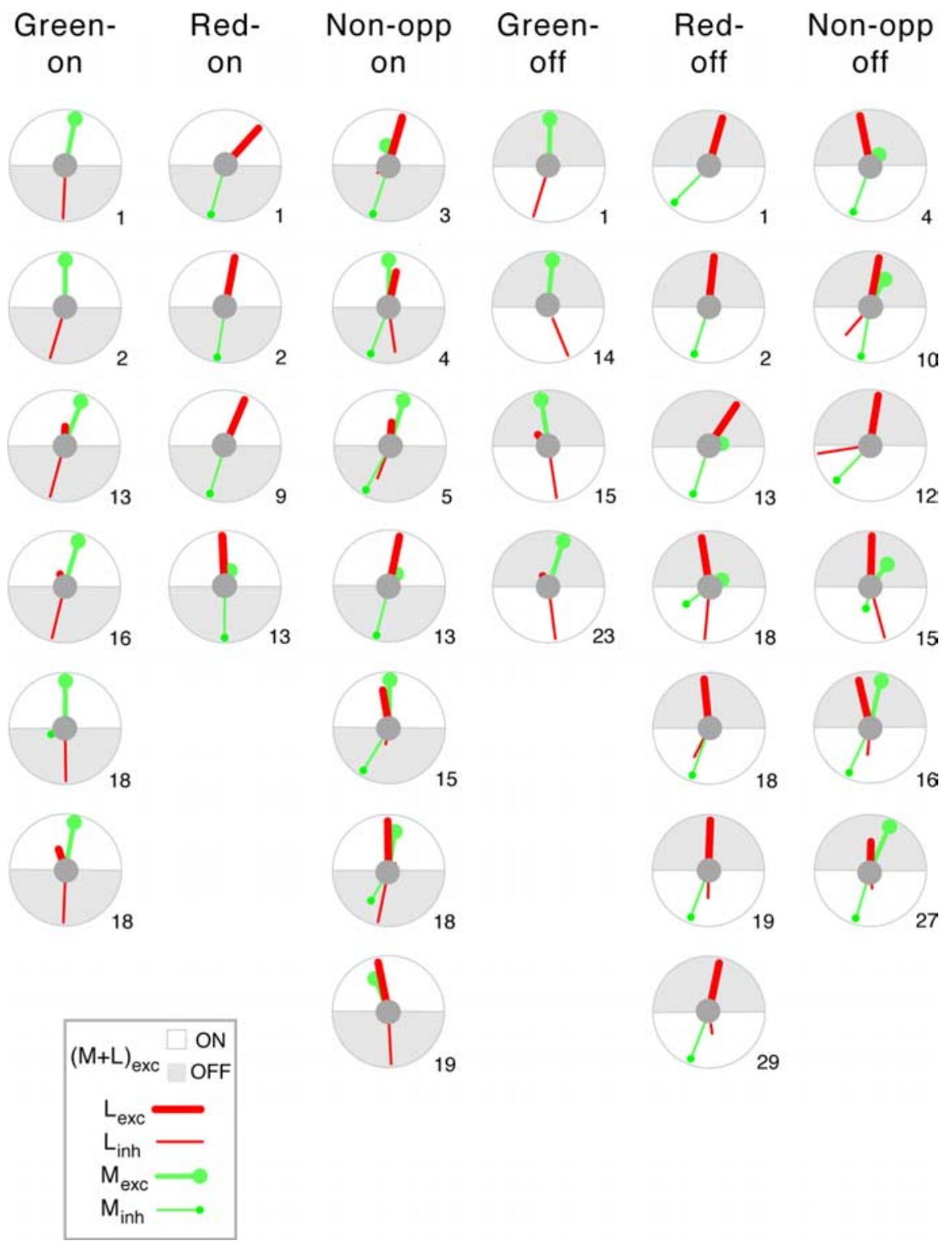

Figure 7. Phase and amplitude of cone inputs to parvocellular cells. Each column shows one cell category. For each cell, the vectors show the response phase and relative amplitude of $L$ and $M$ inputs to the receptive field excitatory (exc) center and inhibitory (inh) surround regions. The vertical axis for each cell is set at the response phase for $L+M$ modulation. Weights are independently normalized to the dominant cone for center and surround. Note that mixing of $M$ and $L$ cone inputs to the center is a feature of most non-opponent cells and that the surround of most opponent cells shows limited mixing. The radius of the gray circle at the center of each plot represents $20 \%$ cone weight. Eccentricity (in degrees) is indicated at the bottom right of each plot. cases ( 4 of 34 aperture and 11 of 34 annulus tuning curves), the phase constraints could not be met for both of the cone-isolating conditions (for example, if a cell receives pure $\mathrm{M}$ cone excitation, the phase of $\mathrm{L}$ cone response will never be close to the excitatory response phase). In these cases, the response amplitude for that cone was set to 0 for that condition.

As noted above, under the Gaussian receptive field model, the excitatory and inhibitory mechanisms are spatially overlapping and have infinite extent, so no spatial configuration can segregate these mechanisms completely. We therefore estimated the functional segregation achieved by our optimized stimuli by integrating the two Gaussian components using the receptive field parameters $\sigma_{\text {exc }}, \sigma_{\text {inh }}, a_{\text {exc }}$, and $a_{\text {inh }}$ derived from the $(\mathrm{M}+\mathrm{L})$ spatial frequency tuning function for each cell (Eqs. $2,3)$. These calculations showed maximum $4 \%$ contribution of the inhibitory Gaussian to center-optimized stimuli $(0.024 \pm 0.045$, mean $\pm \mathrm{SD} ; n=34)$. The excitatory Gaussian contribution to surround-optimized stimuli was also low (mean of 0.034 ) but more variable (SD of 0.076 ; range of $0-0.33$ ). These values (together with the response phase criteria described above) give us confidence that our method gives a greater degree of segregation of excitatory and inhibitory input to PC cells than has been achieved previously. We therefore used this method to estimate the $\mathrm{L}$ and $\mathrm{M}$ cone contributions to PC cell center and surround.

\section{Phase and amplitude of cone inputs}

Cone weights and response phase for the 34 PC cells studied are shown as polar plots in Figure 7. Response phase for each cell is referenced to the response phase for center-optimized L + M modulation (vertical axis). Amplitudes are shown relative to the dominant cone for each (excitatory or inhibitory) mechanism. It can be seen that the phases of cone inputs to each (excitatory center and inhibitory surround) region are closely aligned and that center and surround inputs are approximately in opposite temporal phase at the contrast modulation frequency we used $(4 \mathrm{~Hz})$.

The radius of the gray circle at the center of each plot represents $20 \%$ of the dominant cone weight. Thus, it becomes apparent that two-thirds of the opponent PC cells ( 16 of 21 ) show $<20 \%$ cone mixing in the receptive field center. Furthermore, the surround in nearly all ( 20 of 21 ) opponent cells is dominated by the opposite cone type to that which dominates the center. These results show that strong bias in 
cone weights is associated with opponent responses, but that complete segregation of cone types is not essential. In contrast to opponent cells, nearly all (12 of 13) of the non-opponent cells show $>20 \%$ cone mixing to the center mechanism, and the surround of many non-opponent cells ( 8 of 13) is dominated by the same cone type that dominates the center. When considered as an entire population, PC cells show a full range of cone weights, and there are cases in which the distinction between opponent and non-opponent categories is not clearly reflected in differences in cone weight and temporal phase. We interpret this to mean that the high proportion of opponent PC cells is not the result of all-or-none selective wiring. Rather, it is the result of a more subtle process that biases cone weights in favor of opponent inputs to PC cells.

\section{Both center and surround of opponent PC cells shows cone bias}

We quantified the degree of cone segregation by the relative weight $[\mathrm{L} /(\mathrm{L}+\mathrm{M})]$, or by cone purity, which describes the ratio of $\mathrm{L}-\mathrm{M}$ difference to the total subunit weight (Mullen and Kingdom, 1996). A cone purity value of 0 means equal weight of $\mathrm{L}$ and $\mathrm{M}$ cones, whereas 1 means functional input from either $\mathrm{L}$ or $\mathrm{M}$ cones alone. Opponent purity describes the overall segregation of $\mathrm{L}$ and $\mathrm{M}$ cones between center and surround and is calculated as the absolute difference in $\mathrm{L}$ cone ratio between center and surround (Mullen and Kingdom, 1996): $[\mathrm{L} /(\mathrm{L}+\mathrm{M})]_{\mathrm{ce}}-$ $[\mathrm{L} /(\mathrm{L}+\mathrm{M})]_{\mathrm{su}}$, where ce is center and su is surround. An opponent purity value of 0 means identical cone ratios, whereas 1 indicates a perfectly cone-opponent receptive field (pure L center and pure $\mathrm{M}$ surround or vice versa). Figure $8, A$ and $B$, shows the result.

For opponent cells, the cone purity of both the center and surround is greater (median center purity, 0.65; median surround purity, $0.93 ; n=21$ ) than for non-opponent cells (median center purity, 0.29 ; median surround purity, $0.35 ; n=13 ; p<$ 0.01, unpaired Wilcoxon's test). Furthermore, for opponent cells, the surround cone purity is at least as high as the center cone purity ( $n=21 ; p=0.204$, unpaired Wilcoxon's test), despite the fact that the surround draws input from a larger number of cones: in our sample, the surround diameter is, on average, 6.29 times larger than the center diameter. Finally, we found significant negative correlation $(r=-0.79 ; p<0.001)$ between center and surround cone weights, so cells with $\mathrm{L}$ cone-dominated centers tend to have $\mathrm{M}$ cone-dominated surrounds and vice versa (Fig. $8 A$ ). These results all are consistent with preferential, but not exclusive, selection of opponent cone types in the receptive fields of opponent PC cells.

Figure $8 B$ shows that opponent PC cells are characterized by overall imbalance of cone types driving the centers and surround rather than exclusive cone inputs to either mechanism. In Figure $8 C$, the ratio of chromatic to luminance gain is plotted against opponent purity. The strength of opponent response is in approximately exponential relationship to opponent purity (correlation between $\log$ gain ratio $[\mathrm{L}-\mathrm{M}] /[\mathrm{L}+\mathrm{M}]$ and opponent purity, $r=0.58$; $p<0.01$ ). Our criterion value for classifying cells as opponent therefore represents an opponent purity close to 0.5 . Cells above this opponent purity value show average $(\mathrm{L}+\mathrm{M})$ / $(\mathrm{L}-\mathrm{M})$ gain ratio 5.7-fold greater than cells below this value. The opponent purity of green-On and green-Off cells (0.78 \pm 0.14 , mean $\pm \mathrm{SD} ; n=10)$ is slightly greater than opponent purity of red-On and red-Off cells $(0.67 \pm 0.26$, mean $\pm \mathrm{SD} ; n=11)$,
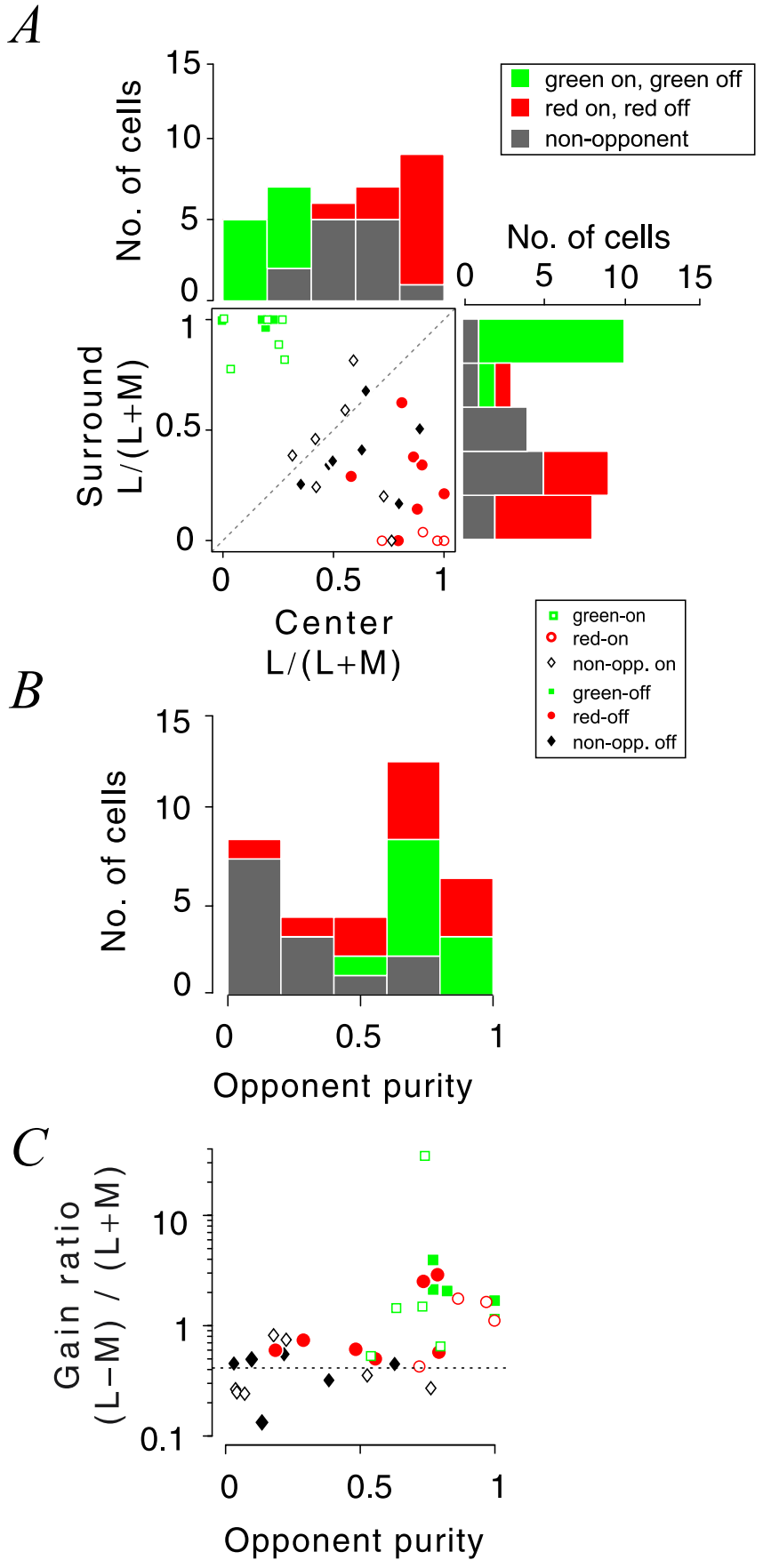

Figure 8. Relationship of cone segregation to chromatic sensitivity. $A$, Cone purity of excitatory center and inhibitory surround inputs to $\mathrm{PC}$ cells. Across the entire $\mathrm{PC}$ population, the full range of cone weight is exhibited by the surround as well as by the center mechanism, but opponent cells show high cone purity in both center and surround. There is also a negative correlation $(r=-0.79 ; p<0.001)$ between excitatory and inhibitory cone weight. $\boldsymbol{B}, 0$ pponent purity. Most opponent neurons show opponent purity close to 1 (pure and opposite $L$ and $M$ weights in center and surround), whereas non-opponent cells are closer to 0 (equal cone weights in center and surround). C, Relationship of chromatic response selectivity to opponent purity. Here, $(L-M) /(L+M)$ shows the relative redgreen $(L-M)$ and luminance $(L+M)$ contrast gain. Dashed line shows the gain ratio in which the $L-M$ and $L+M$ stimuli yield the same cone contrast.

but the difference is not significant ( $p=0.47$, unpaired Wilcoxon's test). In summary, a cone weight difference of $\sim 2: 1$ between center and surround is sufficient to produce robust chromatic opponent responses in PC cells. 
Opponent purity is greater than predicted by random wiring A "hit-and-miss" binomial model of $\mathrm{L}$ and $\mathrm{M}$ cone inputs to PC receptive fields (Mullen and Kingdom, 1996) can be used to predict opponent purity of a randomly wired PC cell given knowledge of the number of cones converging to the receptive field center mechanism. We therefore used our estimates of cone convergence to PC cells in our dataset (see above, Fig. 4) to compare the predictions of the random wiring hypothesis with our measured values. We simplified the comparison by using the same $\mathrm{L} / \mathrm{M}$ cone ratio (1:1) and ratio of center and surround cone numbers (1:6) as shown by Mullen and Kingdom (1996), their Figure $1 B$. This choice is justified on three grounds. First, the average $\mathrm{L} / \mathrm{M}$ cone ratio in marmoset retina is expected to be close to $1: 1$ (Lyon, 1972; Travis et al., 1988; Tovée, 1993; Bowmaker et al., 2003) (see Discussion). Second, even twofold changes in the L/M ratio have only small effects on average opponent purity (Mullen and Kingdom, 1996). Third, on average, the radius of surround that we measured is $\sim 6$ times larger than center radius, consistent with a surround to center cone number ratio of at least $6: 1$. Values from the published figure were fit to the form

$$
c_{1} e^{-\lambda_{1} n}+c_{2} e^{-\lambda_{2} n}
$$

where $c_{1}=1.0813, c_{2}=0.2723, \lambda_{1}=1.5079, \lambda_{2}=0.0647$, and $n$ is the number of cones in the receptive field center. This enables the opponent purity for a given value of cone convergence to be estimated.

The result of this procedure is shown in Figure 9A. As expected, the maximum opponent purity $(0.5)$ is predicted for foveal PC cells, because they show one-to-one cone convergence to the receptive field center and, on average, equal weight of $L$ and $M$ cones in the surround. Opponent purity is predicted to fall rapidly with increasing convergence, so that cells outside the fovea [which receive convergent input from at least eight cones to the receptive field center (Fig. 4C)] are predicted to have opponent purity below 0.2 .

Measured and predicted opponent purity are compared for each cell in Figure 9B. For nearly all PC cells (31 of 34, 91\%) the measured opponent purity is greater than predicted by the random wiring (hit-and-miss) model. On average, measured opponent purity $(0.55 \pm 0.32$, mean $\pm \mathrm{SD} ; n=34)$ is more than double the value predicted by random wiring $(0.21 \pm 0.22$, mean $\pm \mathrm{SD} ; p<0.01$, paired Wilcoxon's test). This result is consistent with the results shown in Figures 7 and 8. The functional bias for either $\mathrm{L}$ or $\mathrm{M}$ cones to dominate in the surround and the negative correlation between center and surround cone weight both serve to "push" opponent purity above the average predicted by random wiring. A more extensive modeling study could incorporate stochastic variation in cone weight to predict not only the average value but also the proportion of opponent PC cells at each eccentricity. We did not attempt this exercise.

\section{Contrast saturation could enhance PC responses to low-contrast chromatic stimuli}

The approximately exponential relationship between chromatic response amplitude and opponent purity (Fig. $8 C$ ) suggests that responses to chromatic contrast are selectively enhanced in PC cell receptive fields. A possible basis for this effect is shown in Figure 10, in which we compare responses to cone-isolating and $\mathrm{L}-\mathrm{M}$ modulation across the PC population and across all aperture sizes. Figure $10 \mathrm{~A}$ compares for one green-Off cell the aperture tuning curves for $\mathrm{L}$ cone (red circles) and $\mathrm{M}$ cone (green squares) modulation. The cone contrast for both conditions is
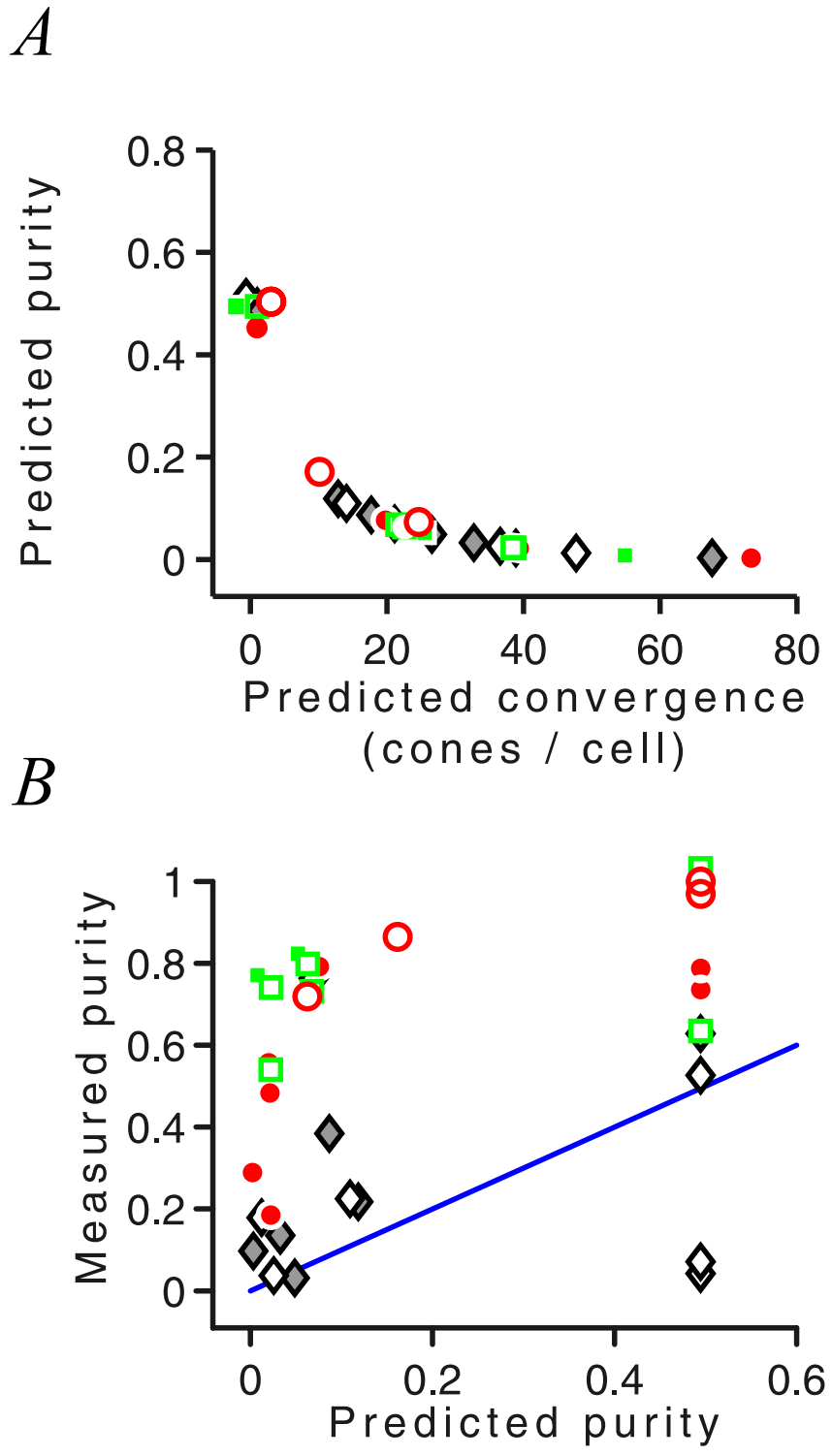

Figure 9. Predictions of the random wiring hypothesis. $A$, Opponent purity predicted according to the hit-and-miss model of Mullen and Kingdom [(1996) their Fig. 1B]. The number of cones in the receptive field center of each $\mathrm{PC}$ cell was estimated from the predicted cone convergence (calculated as shown in Fig. 4). B, Comparison of predicted and measured opponent purity. The solid line has a slope of 1 . Symbols as in Figure 8

close to $36 \%$. Figure $10 \mathrm{~B}$ shows the response of this cell to $\mathrm{L}-\mathrm{M}$ modulation (gray diamonds), in which the $\mathrm{M}$ and $\mathrm{L}$ cone contrast is close to $18 \%$ but the cones are activated in opposite temporal phase. The solid line shows the vector (phase and amplitude) sum of the $\mathrm{M}$ and $\mathrm{L}$ cone stimuli from Figure $10 \mathrm{~A}$, scaled for cone contrast. The $\mathrm{L}-\mathrm{M}$ response amplitude falls close to the vector sum prediction for apertures below $1^{\circ}$ diameter but lies above the vector sum prediction for larger apertures. Thus, for these apertures, the response is enhanced by out-of-phase combination of two low-contrast $(\sim 18 \%)$ components relative to the prediction given by higher-contrast $(\sim 36 \%)$ stimuli.

Figure $10 \mathrm{C}$ shows that, overall, the magnitude of the enhancement effect is small; across all cells and stimulus conditions, there is tight correlation $\left(r^{2}=0.82\right)$ between predicted and actual response. This is consistent with other evidence that PC cells show close to linear combination of $\mathrm{M}$ and $\mathrm{L}$ cone inputs (Derrington et al., 1984; Smith et al., 1992; Reid and Shapley, 2002). The effect 
A



B

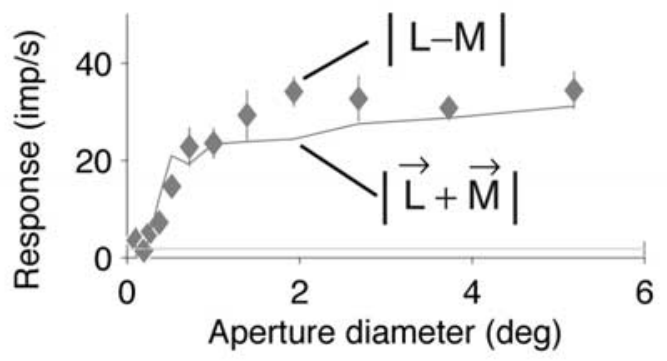

C

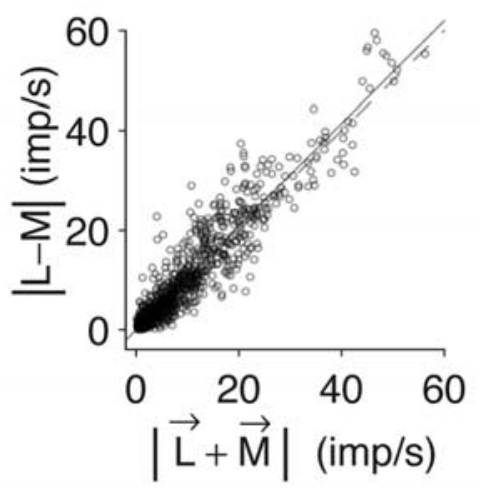

D

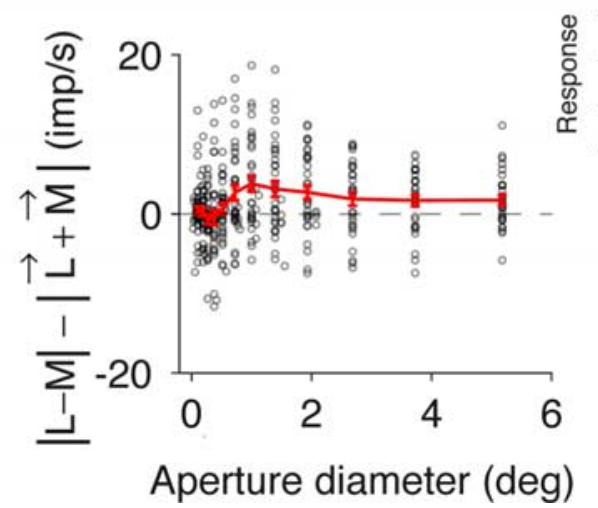

Figure 10. Linearity of cone summation in PC cells. $\boldsymbol{A}$, Response amplitude for M coneisolating apertures (open squares) and $\mathrm{L}$ cone-isolating apertures (filled circles) in a green-0ff cell. Curves show difference-of-Gaussians fits. $\boldsymbol{B}$, Response of this cell to chromatic modulation (gray diamonds). The gray line joins the predictions for each aperture size of the (contrastscaled) vector sum of the cone-isolating conditions. The fit is good but underestimates slightly the responses to intermediate and large apertures. C, Scatter plot of the vector sum predicted amplitude ( [vector] $\mathrm{L}+$ [vector]M ) against measured response amplitude for chromatic modulation ( $L-M$ ) pooled across all stimulus conditions for all cells. $D$, Prediction discrepancy as a function of aperture sizes. Filled squares show means. Error bars show SEM. The discrepancy is positive for all aperture diameters greater than $1^{\circ}$. The inset illustrates how response saturation for the high-contrast cone-isolating stimuli could generate the discrepancy, if responses to the low-contrast components of the chromatic stimulus were combined before the saturation stage. is greatest at apertures close to $1^{\circ}$ (Fig. $10 \mathrm{D}$ ). There are at least two simple explanations for the nonlinear relationship between opponent purity and opponent response amplitude. First, the combination of low-contrast components of the $\mathrm{L}-\mathrm{M}$ stimulus produces negligible response saturation at a point before the opponent site (Fig. $10 D$, inset). Second, response rectification at high contrasts could lead to underestimation of response amplitude by the fundamental Fourier component. More comprehensive tests of these hypotheses require systematic variation of cone contrast and maintained response amplitude.

\section{Discussion}

Is the random wiring hypothesis still tenable?

When the entire PC population is considered, one key prediction of the random wiring hypothesis is supported by our data. That is, cone-opponent responses are degraded by mixed cone inputs to the receptive field center. However, our data also show that functional input from a single ( $\mathrm{L}$ or $\mathrm{M}$ ) cone to the receptive field center may be sufficient, but is not necessary, for cone opponency. Furthermore, our results do not support the prediction that the inhibitory input to PC cells is constituted of an average of the local $\mathrm{L} / \mathrm{M}$ cone ratio. This suggests that, in the absence of selective wiring for the receptive field center mechanism, additional factors operate to bias the functional segregation of cone inputs to PC cells. In the following, we suggest that a "random wiring, functional bias" model may give a better account of PC cell responses than a purely random model.

Our foveal data are consistent with previous studies of marmoset foveal receptive fields, as well as results from four species of macaque (Macacca fascicularis, M. mulatta, M. iris, and M. nemestrina) and two species of New World monkeys (Cebus apella and Alouatta caraya). These results were obtained using several different techniques: temporal and/or spatial analysis of cone signatures (Derrington et al., 1984; Kaplan et al., 1989; Smith et al., 1992; Kremers et al., 1998; Lankheet et al., 1998a), pseudorandom ("M-sequence") modulation of gratings or cone-isolating checkerboards (Gielen et al., 1982; Benardete and Kaplan, 1999; Reid and Shapley, 2002), and counterphase modulation of bipartite fields (Lee et al., 1998). All of these studies are consistent with the presence of cone-selective inputs to the surround mechanism of opponent PC cells. In common with previous recordings from macaque retina and geniculate (Wiesel and Hubel, 1966; DeMonasterio et al., 1975; Dreher et al., 1976), we found a small number of non-opponent PC cells with receptive fields below $5^{\circ}$ eccentricity ( 4 of 13), although this is well within the eccentricity range $\left(<10^{\circ}\right)$ of one-to-one connections between midget bipolar and midget ganglion cells in marmoset (Wilder et al., 1996; Chan et al., 2001). We never encountered non-opponent PC cells under $2^{\circ}$ eccentricity, suggesting that the PC cells in the centralmost fovea may be exclusively opponent, but our sample is too small to draw a firm conclusion.

Our data from peripheral retina are primarily consistent with results obtained from PC ganglion cells in peripheral macaque retina (Martin et al., 2001; Solomon et al., 2005). In contrast, Diller et al. (2004) measured light-evoked responses of macaque ganglion cells in vitro and found little sign of cone opponency in PC cells at eccentricities above $30^{\circ}$. It was later shown that the high $(\sim 10 \mathrm{~Hz})$ modulation frequency of stimulation used by these authors would not detect opponent PC cells in the peripheral retina, in which opponent responses are limited to low temporal frequencies (Solomon et al., 2005). Despite this limitation, the study by Diller et al. and by others in macaque retina (DeMonasterio and Gouras, 1975; DeMonasterio et al., 1975; Diller 
et al., 2004; Solomon et al., 2005) do agree that the proportion of opponent PC cells declines at eccentricities above $40^{\circ}$.

\section{Determinants of chromatic gain}

Early studies categorized PC cells as possessing either nonopponent or opponent receptive fields (DeValois et al., 1966; Wiesel and Hubel, 1966; DeMonasterio and Gouras, 1975), but this dichotomy was questioned by later studies that measured the relative cone weights of inputs to PC cells (Derrington et al., 1984; Lee et al., 1987; Smith et al., 1992). Our results suggest a simple explanation for this apparent discrepancy. Because chromatic response amplitude and opponent purity show an approximately exponential relationship, measurements of chromatic response amplitude (that is, the $y$-axis in Fig. $8 C$ ) would naturally yield a "cluster" of opponent cells, whereas measurement of relative cone weight (that is, the $x$-axis in Fig. $8 C$ ) would yield a broad distribution, consistent with a continuum of opponent response property. For most PC cells in our dataset, the cone bias of the center is normally opposite to that in the surround (Figs. 7, 8C). Although the reason for this differential bias is not clear, it should nevertheless work to preserve chromatic opponent responses, even as the size of PC receptive grows larger in the peripheral retina.

\section{Source of functional bias in excitation}

Direct visualization of the cone mosaic has shown for humans and macaque monkeys that the $\mathrm{L}$ and $\mathrm{M}$ cones are distributed randomly and that there is substantial intersubject variation in the average $\mathrm{L} / \mathrm{M}$ cone ratio for human observers (Roorda et al., 2001; Hofer et al., 2005). The L and M mosaic in marmosets is governed by the process of X-inactivation or "Lyonization" (Lyon, 1972; Travis et al., 1988; Tovée, 1993) and comprises patches made up of clonal descendents of cells expressing either the maternal or paternal photopigment. The size of these patches in peripheral marmoset retina is not known, but limited microphotometric recordings from the fovea are consistent with a random arrangement (Bowmaker et al., 2003). Thus, different mechanisms determine the $\mathrm{L} / \mathrm{M}$ mosaic in marmosets and macaques (Hunt et al., 1993; Tovée, 1993; Nathans, 1999; Wang et al., 1999), yet the processes both result in a matrix that is much closer to random arrangement than, say, the crystalline chromatic lattice of cones in the retina of fishes (Lythgoe and Partridge, 1989). Anatomical analysis has shown directly that marmoset PC cells are not selectivity wired to a subset of bipolar cells in the dendritic field (Jusuf et al., 2006a,b), and data from other primate retinas are consistent with random wiring at the level of ganglion cell dendrites (Dacey, 1993; Yamada et al., 1996; Calkins and Sterling, 1999). This all suggests that the high center cone purity in opponent PC cells arises from functional input from a single "patch" of like-type (L or M) cones in the periphery rather than selective wiring of ganglion cells for individual members of the L or M cone mosaic, as previously speculated (Dacey, 1993; Martin et al., 2001).

In many other respects studied so far, the anatomical and physiological properties of marmoset and macaque visual system are quantitatively comparable (Yeh et al., 1995a; Ghosh et al., 1996; White et al., 1998; Kilavik et al., 2003), and behavioral tests show that trichromatic New World monkeys display chromatic color discrimination capacity (Jacobs et al., 1987; Tovée et al., 1992). We cannot rule out the possibility that New and Old World primates have achieved post-receptoral cone selectivity by different routes, but it is reasonable to assume that our results would apply to the PC pathway in Old World primates. Indeed, our results can reconcile apparent contradictions in previous studies in macaque by showing that chromatic opponency depends on an overall imbalance of $\mathrm{L}$ and $\mathrm{M}$ inputs to center and surround rather than exclusive input from one cone type to either region.

\section{Source of functional bias in inhibition}

Although our results are broadly consistent with random wiring of inputs to the receptive field center mechanism, the high cone purity in PC receptive field surrounds (Fig. 7) and the negative correlation between center and surround cone weight (Fig. 8A) suggest that inhibitory mechanisms, and their interaction at the cone-opponent site, are at least as important as the properties of the center mechanism in generating opponent PC receptive fields.

We measured surround weights using an annular stimulus, so our measurements do not include the contribution of the inhibitory mechanism to the receptive field center (Fig. $5 F, H$ ). Although under the Gaussian receptive field model this contribution is very small $(<5 \%)$, an in vitro analysis of the $\mathrm{H} 1$ class of horizontal cell receptive fields was consistent with a sensitivity profile, which shows a sharper peak than a Gaussian profile (Packer and Dacey, 2002). The fact that $\mathrm{H} 1$ cells contact both $\mathrm{L}$ and M cones (Dacey et al., 1996; Goodchild et al., 1996) implies that this inhibitory contribution to the centralmost cones in the receptive field would thus be mixed. Regardless of this possibility, our data show that, for the majority of PC cells, cone-selective inhibition can be elicited by annuli that are spatially remote from the receptive field center. This is existent proof for functional cone bias of inhibitory inputs to PC cells, but there may be some mixed $\mathrm{L} / \mathrm{M}$ cone inhibition in which the inhibitory mechanism overlaps with the center. In summary, the local inhibitory influence of horizontal cells may contribute to both spatial and chromatic opponency yet may not be the critical locus for coneselective inhibition. A network involving amacrine cells or amacrine-ganglion cell interactions becomes an equally likely candidate (Mills and Sperling, 1990; Taylor, 1999; Flores-Herr et al., 2001; Kenyon et al., 2004), but the details of this anatomical wiring are not established. Our results suggest that, whatever mechanism is at work, it is most likely common to central and mid-peripheral retina.

\section{References}

Benardete EA, Kaplan E (1999) Dynamics of primate P retinal ganglion cells: responses to chromatic and achromatic stimuli. J Physiol (Lond) 519:775-790.

Blessing EM, Solomon SG, Hashemi-Nezhad M, Morris BJ, Martin PR (2004) Chromatic and spatial properties of parvocellular cells in the lateral geniculate nucleus of the marmoset (Callithrix jacchus). J Physiol (Lond) 557:229-245.

Bowmaker JK, Parry JWL, Mollon JD (2003) The arrangement of L and M cones in human and a primate retina. In: Normal and defective colour vision (Mollon JD, Pokorny J, Knoblauch K, eds). Oxford: Oxford UP.

Calkins DJ, Sterling P (1996) Absence of spectrally specific lateral inputs to midget ganglion cells in primate retina. Nature 381:613-615.

Calkins DJ, Sterling P (1999) Evidence that circuits for spatial and color vision segregate at the first retinal synapse. Neuron 24:313-321.

Calkins DJ, Schein SJ, Tsukamoto Y, Sterling P (1994) M and L cones in macaque fovea connect to midget ganglion cells by different numbers of excitatory synapses. Nature 371:70-72.

Chan TL, Martin PR, Clunas N, Grünert U (2001) Bipolar cell diversity in the primate retina: morphologic and immunocytochemical analysis of a New World monkey, the marmoset Callithrix jacchus. J Comp Neurol 437:219-239.

Croner LJ, Kaplan E (1995) Receptive fields of P and M ganglion cells across the primate retina. Vision Res 35:7-24. 
Dacey DM (1993) The mosaic of midget ganglion cells in the human retina. J Neurosci 13:5334-5355.

Dacey DM, Lee BB, Stafford DK, Pokorny J, Smith VC (1996) Horizontal cells of the primate retina: cone specificity without spectral opponency. Science 271:656-659.

DeMonasterio FM, Gouras P (1975) Functional properties of ganglion cells of the rhesus monkey retina. J Physiol (Lond) 251:167-195.

DeMonasterio FM, Gouras P, Tolhurst DJ (1975) Concealed colour opponency in ganglion cells of the Rhesus monkey retina. J Physiol (Lond) 251:217-229.

Derrington AM, Lennie P (1984) Spatial and temporal contrast sensitivities of neurones in lateral geniculate nucleus of macaque. J Physiol (Lond) 357:219-240.

Derrington AM, Krauskopf J, Lennie P (1984) Chromatic mechanisms in lateral geniculate nucleus of macaque. J Physiol (Lond) 357:241-265.

DeValois RL, Abramov I, Jacobs GH (1966) Analysis of response patterns of LGN cells. J Opt Soc Am 56:966-977.

Diller L, Packer OS, Verweij J, McMahon MJ, Williams DR, Dacey DM (2004) L and M cone contributions to the midget and parasol ganglion cell receptive fields of macaque monkey retina. J Neurosci 24:1079-1088.

Dreher B, Fukada Y, Rodieck RW (1976) Identification, classification and anatomical segregation of cells with X-like and Y-like properties in the lateral geniculate nucleus of Old-World primates. J Physiol (Lond) 258:433-452.

Enroth-Cugell C, Robson J (1966) The contrast sensitivity of retinal ganglion cells of the cat. J Physiol (Lond) 187:517-552.

Flores-Herr N, Protti DA, Wässle H (2001) Synaptic currents generating the inhibitory surround of ganglion cells in the mammalian retina. J Neurosci 21:4852-4863.

Forte J, Peirce JW, Kraft JM, Krauskopf J, Lennie P (2002) Residual eyemovements in macaque and their effects on visual responses of neurons. Vis Neurosci 19:31-38.

Forte J, Blessing EM, Buzás P, Martin PR (2006) Contribution of chromatic aberrations to color signals in the primate visual system. J Vis 6:97-105.

Frishman LJ, Freeman AW, Troy JB, Schweitzer-Tong DE, Enroth-Cugell C (1987) Spatiotemporal frequency responses of cat retinal ganglion cells. J Gen Physiol 89:599-628.

Ghosh KK, Goodchild AK, Sefton AE, Martin PR (1996) Morphology of retinal ganglion cells in a New World monkey, the marmoset Callithrix jacchus. J Comp Neurol 366:76-92.

Gielen CCAM, van Gisbergen JAM, Vendrik AJH (1982) Reconstruction of cone-system contributions to responses of colour-opponent neurones in monkey lateral geniculate. Biol Cybern 44:211-221.

Goodchild AK, Chan TL, Grünert U (1996) Horizontal cell connections with short-wavelength-sensitive cones in macaque monkey retina. Vis Neurosci 13:833-845.

Hofer H, Carroll J, Neitz J, Neitz M, Williams DR (2005) Organization of the human trichromatic cone mosaic. J Neurosci 25:9669-9679.

Hunt DM, Williams AJ, Bowmaker JK, Mollon JD (1993) Structure and evolution of the polymorphic photopigment gene of the marmoset. Vision Res 33:147-154.

Jacobs GH, Neitz J, Crognale M (1987) Color vision polymorphism and its photopigment basis in a callitrichid monkey (Saguinus fuscicollis). Vision Res 27:2089-2100.

Jusuf PR, Martin PR, Grünert U (2006a) Synaptic connectivity in the midget-parvocellular pathway of primate retina. J Comp Neurol 494:260-274.

Jusuf PR, Martin PR, Grunert U (2006b) Random wiring in the midget pathway of primate retina. J Neurosci 26:3908-3917.

Kaplan E, Shapley RM, Purpura K (1989) Spatial and spectral mechanisms of primate retinal ganglion cells. In: Seeing contour and colour (Kulikowski JJ, Dickinson CM, Murray IJ, eds), pp 36-40. Oxford: Pergamon.

Kenyon GT, Theiler J, George JS, Travis BJ, Marshak DW (2004) Correlated firing improves stimulus discrimination in a retinal model. Neural Comput 16:2261-2291.

Kilavik BE, Silveira LC, Kremers J (2003) Centre and surround responses of marmoset lateral geniculate neurones at different temporal frequencies. J Physiol (Lond) 546:903-919.

Kolb H, Dekorver L (1991) Midget ganglion cells of the parafovea of the human retina: a study by electron microscopy and serial section reconstructions. J Comp Neurol 303:617-636.
Kremers J, Weiss S (1997) Receptive field dimensions of lateral geniculate cells in the common marmoset (Callithrix jacchus). Vision Res 37:2171-2181.

Kremers J, Zrenner E, Weiss S, Meierkord S (1998) Chromatic processing in the lateral geniculate nucleus of the common marmoset (Callithrix jacchus). In: Color vision—perspectives from different disciplines (Backaus W, Kliegl R, Werner JS, eds), pp 89-99. Berlin: de Gruyter.

Kremers J, Kozyrev V, Silveira LC, Kilavik BE (2004) Lateral interactions in the perception of flicker and in the physiology of the lateral geniculate nucleus. J Vis 4:643-663.

Kuffler SW (1953) Discharge patterns and functional organization of mammalian retina. J Neurophysiol 16:37-68.

Lankheet MJM, Lennie P, Krauskopf J (1998a) Distinctive characteristics of subclasses of red-green P-cells in LGN of macaque. Vis Neurosci 15:37-46.

Lankheet MJM, Lennie P, Krauskopf J (1998b) Temporal-chromatic interactions in LGN P-cells. Vis Neurosci 15:47-54.

Lee BB, Valberg A, Tigwell DA, Tryti J (1987) An account of responses of spectrally opponent neurons in macaque lateral geniculate nucleus to successive contrast. Proc R Soc Lond B Biol Sci 230:293-314.

Lee BB, Pokorny J, Smith VC, Martin PR, Valberg A (1990) Luminance and chromatic modulation sensitivity of macaque ganglion cells and human observers. J Opt Soc Am A 7:2223-2236.

Lee BB, Kremers J, Yeh T (1998) Receptive fields of primate retinal ganglion cells studied with a novel technique. Vis Neurosci 15:161-175.

Lee BB, Silveira LCL, Yamada ES, Hunt DM, Kremers J, Martin PR, Troy JB, daSilva M (2000) Visual responses of ganglion cells of a New-World primate, the capuchin monkey, Cebus apella. J Physiol (Lond) 528:573-590.

Lennie P, Haake PW, Williams DR (1991) The design of chromatically opponent receptive fields. In: Computational models of visual processing (Landy MS, Movshon JA, eds), pp 71-82. Cambridge, MA: MIT.

Lenth RV (2006) Java applets for power and sample size, version 1.63. http://www.stat.uiowa.edu/ rlenth/Power.

Lyon MF (1972) X-Chromosome inactivation and developmental patterns in mammals. Biol Rev 47:1-35.

Lythgoe JN, Partridge JC (1989) Visual pigments and the acquisition of visual information. J Exp Biol 146:1-20.

Martin PR, Lee BB, White AJR, Solomon SG, Rüttiger L (2001) Chromatic sensitivity of ganglion cells in the peripheral primate retina. Nature 410:933-936.

Mills SL, Sperling HG (1990) Red/green opponency in the rhesus macaque ERG spectral sensitivity is reduced by bicuculline. Vis Neurosci 5:217-221.

Mollon JD, Bowmaker JK, Jacobs GH (1984) Variations of colour vision in a New World primate can be explained by polymorphism of retinal photopigments. Proc R Soc Lond B Biol Sci 222:373-399.

Mullen KT, Kingdom FAA (1996) Losses in peripheral colour sensitivity predicted from "hit and miss" post-receptoral cone connections. Vision Res 36:1995-2000.

Nathans J (1999) The evolution and physiology of human color vision: insights from molecular genetic studies of visual pigments. Neuron 24:299-312.

Packer OS, Dacey DM (2002) Receptive field structure of H1 horizontal cells in macaque monkey retina. J Vis 2:272-292.

Passaglia CL, Troy JB, Ruttiger L, Lee BB (2002) Orientation sensitivity of ganglion cells in primate retina. Vision Res 42:683-694.

Reid RC, Shapley RM (2002) Space and time maps of cone photoreceptor signals in macaque lateral geniculate nucleus. J Neurosci 22:6158-6175.

Rodieck RW, Stone J (1965) Analysis of receptive fields of cat retinal ganglion cells. J Neurophysiol 28:833-849.

Roorda A, Metha AB, Lennie P, Williams DR (2001) Packing arrangement of the three cone classes in primate retina. Vision Res 41:1291-1306.

Saito CA, da Silva Filho M, Lee BB, Bowmaker JK, Kremers J, Silveira LCL (2004) Alouatta trichromatic color vision-single-unit recording from retinal ganglion cells and microspectrophotometry. Invest Ophthalmol Vis Sci ARVO Abstr 4276.

Shapley R, Perry VH (1986) Cat and monkey retinal ganglion cells and their visual functional roles. Trends Neurosci 9:229-235.

Smith EL, Chino YM, Ridder WH, Kitagawa K, Langston A (1990) Orientation bias of neurons in the lateral geniculate nucleus of macaque monkeys. Vis Neurosci 5:525-545. 
Smith VC, Lee BB, Pokorny J, Martin PR, Valberg A (1992) Responses of macaque ganglion cells to the relative phase of heterochromatically modulated lights. J Physiol (Lond) 458:191-221.

Solomon SG, Lee BB, White AJ, Rüttiger L, Martin PR (2005) Chromatic organization of ganglion cell receptive fields in the peripheral retina. J Neurosci 25:4527-4539.

Taylor WR (1999) TTX attenuates surround inhibition in rabbit retinal ganglion cells. Vis Neurosci 16:285-290.

Tovée MJ (1993) Colour vision in New World Monkeys and the single-locus X-chromosome theory. Brain Behav Evol 42:116-127.

Tovée MJ, Bowmaker JK, Mollon JD (1992) The relationship between cone pigments and behavioural sensitivity in a New World monkey (Callithrix jacchus jacchus). Vision Res 32:867-878.

Travis DS, Bowmaker JK, Mollon JD (1988) Polymorphism of visual pigments in a callitrichid monkey. Vision Res 28:481-490.

Wang Y, Smallwood PM, Cowan M, Blesh D, Lawler A, Nathans J (1999) Mutually exclusive expression of human red and green visual pigmentreporter transgenes occurs at high frequency in murine cone photoreceptors. Proc Natl Acad Sci USA 96:5251-5256.

Wässle H, Boycott BB, Röhrenbeck J (1989) Horizontal cells in the monkey retina: cone connections and dendritic network. Eur J Neurosci 1:421-435.
Westheimer G (1967) Spatial interaction in human cone vision. J Physiol (Lond) 190:139-154.

White AJR, Goodchild AK, Wilder HD, Sefton AE, Martin PR (1998) Segregation of receptive field properties in the lateral geniculate nucleus of a New-World monkey, the marmoset Callithrix jacchus. J Neurophysiol 80:2063-2076.

White AJR, Solomon SG, Martin PR (2001) Spatial properties of koniocellular cells in the lateral geniculate nucleus of the marmoset Callithrix jacchus. J Physiol (Lond) 533:519-535.

Wiesel TN, Hubel D (1966) Spatial and chromatic interactions in the lateral geniculate body of the rhesus monkey. J Neurophysiol 29:1115-1156.

Wilder HD, Grünert U, Lee BB, Martin PR (1996) Topography of ganglion cells and photoreceptors in the retina of a New World monkey: the marmoset Callithrix jacchus. Vis Neurosci 13:335-352.

Yamada ES, Silveira LC, Perry VH (1996) Morphology, dendritic field size, somal size, density, and coverage of $\mathrm{M}$ and $\mathrm{P}$ retinal ganglion cells of dichromatic Cebus monkeys. Vis Neurosci 13:1011-1029.

Yeh T, Lee BB, Kremers J, Cowing JA, Hunt DM, Martin PR, Troy JB (1995a) Visual responses in the lateral geniculate nucleus of dichromatic and trichromatic marmosets (Callithrix jacchus). J Neurosci 15:7892-7904.

Yeh T, Lee BB, Kremers J (1995b) Temporal response of ganglion cells of the macaque retina to cone-specific modulation. J Opt Soc Am A 12:456-464. 